\title{
Inelastic behavior of cold-formed braced walls under monotonic and cyclic loading
}

\author{
Mohsen Gerami ${ }^{1} \cdot$ Mohsen Lotfi $^{2} \cdot$ Roya Nejat $^{3}$
}

Received: 5 February 2014/ Accepted: 8 April 2015/Published online: 23 April 2015

(c) The Author(s) 2015. This article is published with open access at Springerlink.com

\begin{abstract}
The ever-increasing need for housing generated the search for new and innovative building methods to increase speed and efficiency and enhance quality. One method is the use of light thin steel profiles as load-bearing elements having different solutions for interior and exterior cladding. Due to the increase in CFS construction in lowrise residential structures in the modern construction industry, there is an increased demand for performance inelastic analysis of CFS walls. In this study, the nonlinear behavior of cold-formed steel frames with various bracing arrangements including cross, chevron and k-shape straps was evaluated under cyclic and monotonic loading and using nonlinear finite element analysis methods. In total, 68 frames with different bracing arrangements and different ratios of dimensions were studied. Also, seismic parameters including resistance reduction factor, ductility and force reduction factor due to ductility were evaluated for all samples. On the other hand, the seismic response modification factor was calculated for these systems. It was concluded that the highest response modification factor would be obtained for walls with bilateral cross bracing systems with a value of 3.14. In all samples, on increasing the distance of straps from each other, shear strength increased and shear strength of the wall with bilateral bracing system was $60 \%$ greater than that with lateral bracing system.
\end{abstract}

Mohsen Lotfi

mohsen.lotfi67@yahoo.com

Faculty of Engineering, Semnan University, Semnan, Iran

2 Faculty of Civil Engineering, Semnan University, Semnan, Iran

3 Faculty of Civil Engineering, University of Mohaghegh Ardabili, Ardabili, Iran
Keywords Cold-formed steel frames · Strap brace . Nonlinear analysis - Monotonic and cyclic loading . Behavior factor

\section{Introduction}

Today, the use of cold-formed steel members as structural elements has gained much popularity in the construction of residential and industrial buildings. One proper strategy for improving the seismic behavior of these structures is the use of structural coverage or braces. Braces transmit horizontal forces from floor and ceiling surfaces to the foundation. The overall lateral resistance of structures, hardness and ductility of these systems is not entirely confined to braces; however, the behavior of the wall is under the influence of different members of these structures in the lateral load transfer path such as brace joints, binding sheets, studs, tracks and joints. The National Building Code of Canada (2005) contains a philosophy of basic capacity for seismic design, in which a series of fuse elements is defined in seismic-resistant systems for waste of energy caused by earthquake. Fuse elements are expected to enter the nonlinear region. Other members of the frame are also designed for the capacity of the fuse elements to remain linear and experience minimal nonlinear failure. Usually, elements that play the role of fuse in these structures are braces. In the following, we will address some numerical and laboratory studies conducted by researchers on the behavior of cold-formed steel walls.

Miller and Pekoz (1993) conducted studies on the effect of cover plates on vertical load-carrying capacity of coldformed steel studs. Serrette (1997) conducted both static and cyclic load tests on cold-formed steel walls. Tests included panels with different types of bracing, including 
steel sheet sheathing. The sheathing or bracing was placed on only one side of the panels. The failure of steel sheathed panels resulted from rupture of the steel sheet along the line of screws at the edges. Decreasing the fastener spacing and increasing the steel sheathing thickness were effective in increasing the maximum load.

Gad et al. (1999a, b) presented a detailed investigation of the contribution of plasterboard in the seismic performance of CFS X-strap bracing walls and its relevant structural modification factor using experimental tests with shaker table and numerical studies. The authors reported a wide range of values between 4 and 29 for $R$ factor, though they highlighted that the results were impractical and misleading and needed more number of research studies to be reliable.

Telue and Mahendran (2002) conducted experiments on cold-formed steel frames to investigate the behavior of plaster cover plates in the wall of these frames and concluded that the load-carrying capacity of the studs of wall panels would significantly increase if brace and cover plates were used. Fülöp and Dubina (2004) tested three X-braced screw-connected wall specimens $(3.6 \mathrm{~m}$ long $\times 2.44 \mathrm{~m}$ high) under in-plane lateral loading. Of the three wall specimens, one was tested monotonically and two cyclically. The walls were constructed of a coldformed steel frame. The screw connection configuration was selected to facilitate yielding along the length of the brace, i.e., to avoid net section fracture of the strap through the screw holes. Chord members were constructed of double stud members, such that inelastic deformations and ultimate failure of the walls would be limited to the braces. $\mathrm{U}$ profiles were placed in the tracks at corner locations to increase the hold-down capacity and rigidity. Local buckling of the lower track was observed during loading with damage being concentrated in corner areas. Plastic elongation of the strap did take place; however because of the unexpected failure of the corners, the results of the experiments may not necessarily reflect the true ductility of a braced wall if yielding (and failure) had been limited to the straps. Fülöp and Dubina suggested that the ideal configuration of the corners would be such that the uplift force is directly transmitted from the brace or corner stud to the anchoring bolt, without inducing bending in the bottom track. Failure to strengthen the corners can have a significant effect on the initial rigidity of the system and can be the cause of larger than expected in-plane shear deformations of the wall and premature failure of the braced frame.

Berman et al. (2005) investigated CFS frames using both $\mathrm{X}$-braced and steel-plated shear walls. The main aim of their research was to provide an engineering guideline for evaluating both of these types of CFS walls considering stiffness, ductility and energy dissipation. They reported that the maximum initial stiffness was related to the $\mathrm{X}$-braced frame specimen, while the maximum ductility was provided by steel plate shear wall. Interestingly, using scaled hysteretic results, they found that the energy dissipated was similar for both X-braced frames and steel plate shear walls. Kim et al. (2006) performed a shaker table test on a full-scale two-story one-bay CFS shear panel structure. Each story consisted of two identical shear walls of $2.8 \mathrm{~m}$ length and $3.0 \mathrm{~m}$ height separated from each other by 3.9 m center to center. The two chords were constructed from three C-sections forming a two-cell closed section, and columns were welded to steel anchors and bolted to the slab through the top and bottom tracks. A heavy square RC slab of $4.4 \times 4.4 \mathrm{~m}^{2}$ by $200 \mathrm{~mm}$ thickness along with additional mass was placed at the top of each floor level, which made the total mass at each floor level equal to $256 \mathrm{kN}$. As the second story frame was identical to the first story, the damage occurred mostly in the first story as expected. Connections and anchors to the base beam were designed for the maximum over-strength of straps, based on TI 809-07 (1998) code; however, no pre-tensioning was applied to the tension-only straps in spite of explicit recommendation in the code. The system was completely symmetrical and the centers of mass and stiffness were located at the same point and parallel to shear walls of the structure, to preclude torsional and out-of-plane responses. The structure was then loaded to a normalized accelerogram, which possessed spectral response acceleration equal to the design response spectrum around the fundamental period of the test specimen. The test caused significant yielding in the form of severe nonlinear behavior in the first floor straps along their entire length and yielding of studs near the anchors. The studs did not develop full flexural strength due to local buckling and this impaired their potential contribution to the story shear resistance. The studs' contribution further decreased (about $15 \%$ ) due to anchor deformation, which created a gap between the track and the slab. The results showed that during the large amplitude tests, the X-strap bracing showed very ductile, but highly pinched, hysteretic behavior. The results of this study can be considered conservative because the effect of nonstructural gypsum board cladding was not considered in the test.

Al-Kharat and Rogers (2007) tested 16 sample walls with crossed straps in cold-formed steel frames in laboratory under cyclic and monotonic loading condition. In the research conducted by these researchers, certain criteria for behavior factor have been suggested. Scrutinizing the obtained results and comparing the results to other experiments performed by the authors (Moghimi and Ronagh 2009; Zeynalian and Ronagh 2010a, b) and other researchers show that the X-strap-braced system is considered as a ductile system with a satisfactory shear strength; 
and as such the use of this kind of CFS structure can be preferable particularly in low to medium seismic regions.

Zeynalian and Ronagh (2011) presented a numerical study on seismic characteristics of knee-braced coldformed steel shear walls. A total of 12 models with various ranges of knee elements' lengths were investigated. The numerical models were verified based on experimental tests. Agreement of the numerical simulations and the test results showed that finite element analysis can be used effectively to predict the ultimate capacity of knee-braced CFS shear panels. Of particular interests were the specimens' maximum lateral load capacity and deformation behavior in addition to a rational estimation of the seismic response modification factor. Preliminary conclusions presented in this paper refer to the optimum seismic characteristics of knee-braced CFS shear walls and the corresponding dimensions and configuration.

Pan and Shan (2011) focused on the experimental study of the structural strength of cold-formed steel wall frames with sheathing under monotonic shear loading. Based on the test result analysis, the ductility ratio of the specimen with one-side sheathing was greater than that of the specimen with two-side sheathing. The ultimate strength of wall frame with sheathing increased with increase in the thickness of board.

Zeynaliana et al. (2012) studied the lateral performance of K-braced cold-formed steel structures and their response modification coefficients, $R$ factor. A total of 12 full-scale $2.4 \times 2.4 \mathrm{~m}$ specimens of different configurations were tested under a standard cyclic loading regime. Of particular interest are the specimens' maximum lateral load capacity and deformation behavior as well as a rational estimation of the seismic response modification factor. They concluded that use of a $\mathrm{K}$-stud bracing system is possible only in low seismic regions where the earthquake loads, and thus the required lateral resistance capacity, are not high.

Nithyadharan and Kalyanaraman (2012) presented a numerical model of the hysteretic behavior of such panels, necessary to study the system behavior under various earthquake loading. In this paper, Bouc-Wen-Baber-Noori (BWBN) model is used to capture the deteriorating behaviour, such as the strength and stiffness degradation with severe pinching, observed in the screw connections between the CFS framing members and sheathing, as well as the full wall panels under cyclic loading. The system identification technique based on Nelder and Mead's simplex algorithm is used to identify the unknown parameters of the model. The representation of the constitutive relationship, both under static and cyclic loading of the screw connections and the wall panel sub-system, is demonstrated using the BWBN model.

Zeynalian and Ronagh (2012a, b) studied the seismic performance of strap-brace cold-formed steel shear walls.
This paper presented a nonlinear finite element analyses to optimize the seismic characteristics of strap-braced coldformed steel shear walls enhanced with brackets in the four interior corners of the wall. The numerical models presented here are verified based on experimental tests considering different structural characteristics including: material nonlinearity, geometrical imperfection, residual stresses and perforations. A comparison between the numerical simulations and the test results shows a good agreement proving that finite element analysis can be used effectively to predict the ultimate capacity of strap-braced CFS shear panels. A total of 16 models with different variants of bracket length are investigated. Of particular interest were the specimens' maximum lateral load capacity and deformation behavior in addition to a rational estimation of the seismic response modification factor. Preliminary conclusions presented in this paper refer to the optimum seismic characteristics of strap-braced CFS shear walls and the corresponding dimensions and configuration.

Fiorino et al. (2012) investigated the extensive parametric nonlinear dynamic analysis carried out on one story buildings by means of incremental dynamic analysis (IDA), using an ad hoc model of the hysteresis response of SCFS shear walls. Considering the results of this study, a design nomograph for the seismic design of single-story SCFS frame structures developed on the basis of nonlinear dynamic analysis results is presented. This aims to complete a proposal of a design methodology already presented by the author in the last years.

Dabreo et al. (2014) evaluated the behavior of shear walls made of cold-formed steel sections under gravity and lateral loads. Their investigations showed that using package and design studs based on capacity leads to increase shear strength.

So far, most research has been done on cross bracing systems; while little attention has been given to other bracing arrangements and evaluating their seismic behavior. Despite experiments and studies on cross bracing systems, there exist uncertainties about the exact nonlinear behavior of these systems. To shed light on this significant issue, using modeling, analysis by finite element method, and considering various ratios of height to length of the wall and evaluating nonlinear responses of these systems, we decided to investigate several bracing systems with different arrangements including cross, chevron and $\mathrm{K}$-shape bracings.

\section{Available design guidelines}

AISI standards $(2001 \mathrm{a}, \mathrm{b})$ as one of the pioneer centers working on CFS framing systems prescribe a range of $R$ factors between 2 and 7 for different basic seismic force- 
resisting system, though it emphasizes that some additional essential detailing is needed for $R>3$.

ASCE7 (2005) stipulates that the design of lightweight cold-formed steel structures to resist seismic loads shall be in accordance with the requirements of AISI. However, it requires that for those systems, e.g., a K-braced system, which are not detailed in accordance with AISI, one shall use the $R$ factor designated for "structural steel systems not specifically detailed for seismic resistance" which is equal to 3 .

The American NEHRP recommends seismic provisions FEMA 450 (2003), FEMA P750 (2009) and the Technical Instructions, TI 809-07 (1998), specify that the seismic response modification factor of 4 for diagonal strapping system; for other steel systems such as K-braced configurations, the value of 3 is stipulated.

Also, the Australian cold-formed steel structures standard, AS/NZS 4600-05 (2005), requires that when coldformed steel members are used as the primary earthquakeresisting element, the selected response modification factor shall not be greater than 2, unless specified otherwise.

A simple, but important conclusion from the above review is that there is not a universal agreement on the value of response modification factor, $R$, and in particular there is no reference in the codes specifically for the $R$ factor of systems braced with K-braces. Therefore, more studies are required to clarify this matter.

\section{Basic concepts}

Investigating the parameters of nonlinear behavior and ductility is of utmost importance. These issues are addressed under the rubric of response modification factor.

\section{Stiffness and strength}

The position of the predicted strengths, $S_{\mathrm{yn}}$ and $S_{\mathrm{yp}}$, with respect to $S_{\mathrm{y}}$ may vary from what is illustrated depending on the particular wall being analyzed. The predicted nominal lateral yield strength, $S_{\mathrm{yn}}$, of the wall was based on the tension yield strength of the braces determined using their nominal area (width $\times$ thickness) as well as the minimum specified (nominal) yield stress. The nominal tension yield capacity of the brace was adjusted for the inclined position of the strap members with respect to the horizontal. The predicted nominal lateral shear stiffness of the wall, $\mathrm{kN}$, was calculated based on the axial stiffness of the two tension brace members, which was also adjusted for their inclined position with respect to the horizontal. The predicted values $S_{\mathrm{yn}}$ and $\mathrm{kN}$ represent the nominal (not factored) design parameters that an engineer would typically be able to determine using minimum specified member sizes and material properties without the aid of test results and measurements. $S_{\text {yp }}$ is the predicted lateral yield strength of the wall, which is typically reached when the strap braces yield in tension. $K_{\mathrm{p}}$ is the predicted lateral shear stiffness of the wall, again obtained from the initial elastic axial stiffness of the strap braces alone. The maximum load level reached by each braced wall regardless of the failure mode was defined as the measured yield strength, $S_{\mathrm{y}}$. The measured initial elastic shear stiffness $K_{\mathrm{e}}$, was defined as the secant stiffness from the zero load level to the $40 \%$ of maximum load level, $S_{0.4}$, as recommended in ASTM E2126 (2005) (Fig. 1).

\section{Ductility}

The main factor influencing the behavior factor is the ductility factor. Ductility is, in fact, the ability of bearing nonlinear displacements of the system, so that when the system reaches its yielding capacity, it can still withstand forces until it reaches substantially nonlinear lateral displacement without the structure being collapsed. The ductility of the system has been calculated according to the following equation:

$\mu=\frac{\Delta_{0.8}}{\Delta_{\text {syp }}}$.

In this equation, $\Delta_{\text {syp }}$, is elastic yielding ductility calculated by measuring elastic stiffness $\left(K_{\mathrm{e}}\right)$ and lateral yielding wall resistance $\left(S_{\mathrm{yp}}\right) . \Delta_{0.8}$ is the rate of displacement failure continuing until there is no resistance $(80 \%$ of the ultimate resistance is reduced).

\section{Response modification factor}

The concept of response modification factor is based on the ductile behavior of the structure to absorb seismic energy as well as delay in structure failure. In fact, benefiting from the reality that any structure has a bit additional resistance and ductility, earthquake regulations allow designing structures with less power and they pay the fine of this reduction in force by accepting larger displacements. Research has shown that two factors of additional resistance factor $\left(R_{0}\right)$ and force reduction factor have the greatest impact on the behavior factor at the non-elastic stage due to ductility $\left(R_{\mathrm{d}}\right)$. Behavior response modification factor is written as follows:

$R=R_{0} \times R_{\mathrm{d}}$.

Additional resistance factor $\left(R_{0}\right)$ is the ratio of total yielding limit of structure during the formation of failure mechanism to force corresponding to the formation of the first plastic hinge: 
Fig. 1 Measured and predicted wall strength and stiffness

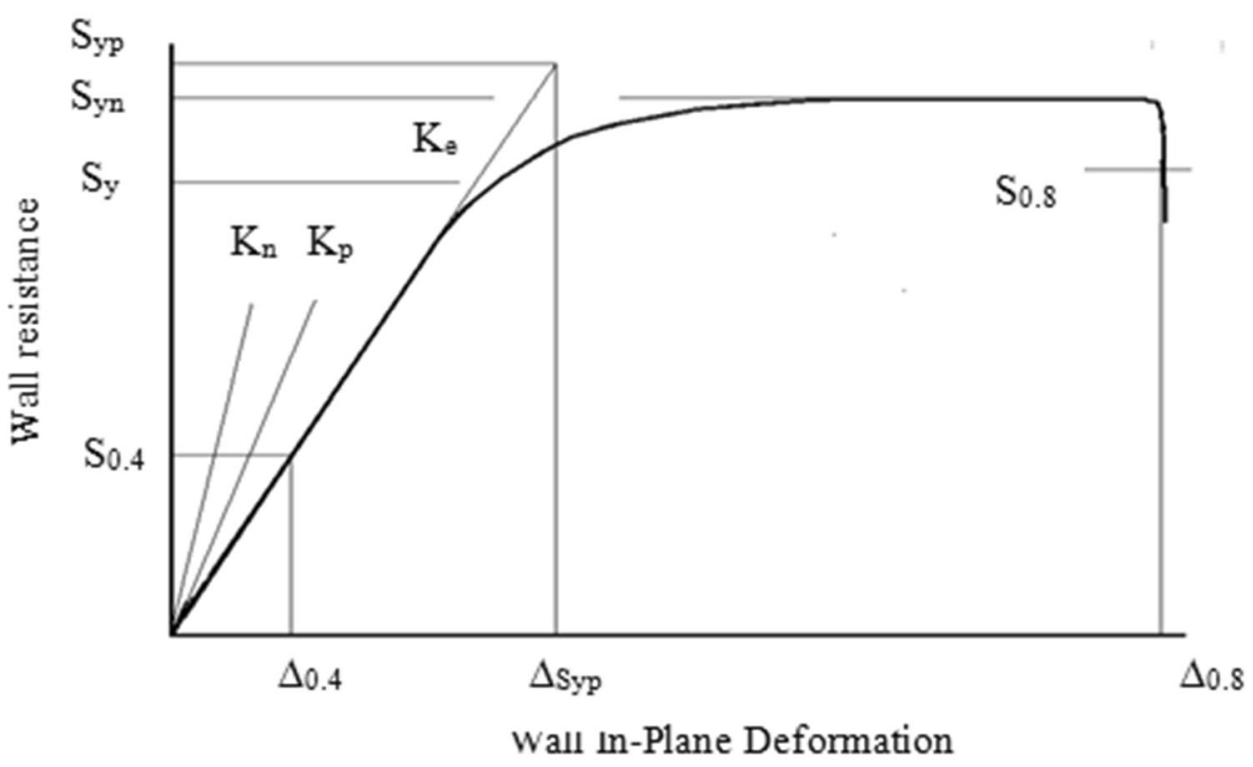

$R_{0}=\frac{S_{\mathrm{y}}}{S_{\mathrm{yn}}}$.

To apply the effect of ductility factor parameter, a factor called force reduction factor due to ductility $\left(R_{\mathrm{d}}\right)$ has been introduced and when the fundamental period of the structure is between 0.1 and $0.5 \mathrm{~s}$, Newmark and Hall (1982) force Equation is calculated as follows:

$R_{\mathrm{d}}=\sqrt{2 \mu-1}$.

\section{Modeling}

In the present study, finite element numerical method was used to model the frames and evaluation of the nonlinear response of belt braces was applied as a lateral bracing system.

\section{Validation of the analytical model with experimental model}

One way to achieve higher confidence in all numerical modeling techniques is to adapt the numerical results with experimental ones. Hence, due to the similarity of the finite element model with the actual conditions, and the possibility of simulating the complexity of potential failure in members and connections and loading conditions, a reasonable model with the lowest error rate can be achieved. In estimating the monotonic behavior of cold-formed steel frames, LSF frame laboratory sample with tape cross brace by Al-Kharat and Rogers (2007) was used. Next, using finite element program and software MSC PATRAN-
NASTRAN (2012), it is modeled and the results of experimental analysis are compared.

\section{The profiles of sections and materials used in the model}

The sample test consisted of braced walls with crossed straps. The height and length of the frames were $2.44 \mathrm{~m}$. Lateral studs made of double C-shaped sections were fused together from the front and the middle studs made of single $\mathrm{C}$-shaped sections were installed with a nominal spacing of $406 \mathrm{~mm}$. Modeling was performed using the same sections. Section profiles and behavior of materials used in double and single studs, tracks and belts are presented in Tables 1 and 2 .

On the other hand, the walls comprised straps that were fillet welded to the gusset plates, which were in turn welded to the stud and track members. Also, flat plate hold downs were placed within the upper and lower tracks at the four corner locations of the wall (Fig. 2).

In terms of ductile seismic performance, the desirable mode of failure of a cold-formed steel braced wall system is generally that of gross cross section yielding of the straps, which form the fuse element in the SFRS. The other elements and connections in the seismic force-resisting system are expected to carry the force associated with the strap yielding load level. The strap braces should be able to enter into the inelastic range of behavior, such that ground motion-induced energy can be dissipated. Ideally, the braces would be able to maintain their yield capacity over extended lateral inelastic displacement of the wall without failure of the connections, gusset plates, tracks, chord studs or hold downs. 
Table 1 Dimension sections and material properties

\begin{tabular}{llll}
\hline Member & Thickness $(\mathrm{mm})$ & Dimensions $(\mathrm{mm})$ & Nominal grade $F_{\mathrm{y}}(\mathrm{MPa})$ \\
\hline Chord studs & 1.91 & $152 \times 41 \times 12.7$ & 345 \\
Interior studs & 1.22 & $152 \times 41 \times 12.7$ & 230 \\
Tracks & 1.91 & $152 \times 31.8$ & 345 \\
Strap bracing & 1.91 & 152 & 230 \\
Connection plate & 1.91 & $300 \times 300$ & 230 \\
\hline
\end{tabular}

Table 2 Matrix of strap-braced wall tests (nominal design dimensions and material properties)

\begin{tabular}{|c|c|c|c|c|c|c|c|}
\hline Member & Nominal thickness (mm) & Thickness (mm) & $\begin{array}{l}\text { Yield stress } \\
F_{\text {y }}(\mathrm{MPa})\end{array}$ & $\begin{array}{l}\text { Ultimate stress } \\
F_{\mathrm{u}}(\mathrm{MPa})\end{array}$ & $F_{\mathrm{u}} / F_{\mathrm{y}}$ & Elng. (\%) & $F_{\mathrm{y}} / F_{\mathrm{yn}}$ \\
\hline Chord studs & 1.91 & 1.91 & 352 & 489 & 1.39 & 35 & 1.02 \\
\hline Interior studs & 1.22 & 1.23 & 336 & 398 & 1.19 & 35 & 1.46 \\
\hline Tracks & 1.91 & 1.94 & 348 & 474 & 1.36 & 37 & 1.01 \\
\hline Strap bracing & 1.91 & 1.83 & 262 & 346 & 1.32 & 38 & 1.14 \\
\hline
\end{tabular}

Fig. 2 Schematic drawing of heavy strap-braced test wall with corner detail
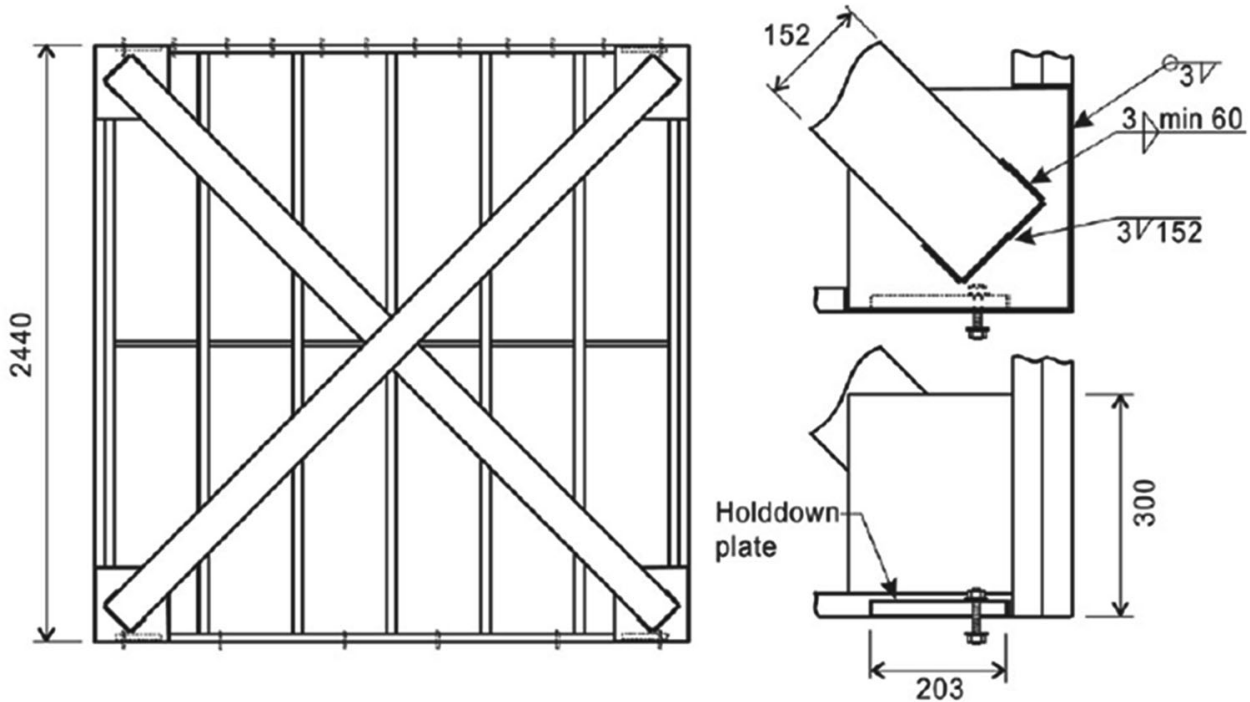

\section{Components used in the analytical model}

The basis of numerical finite element method which is used for solving a variety of engineering problems is the discretization of complex geometric models to easier and smaller elements to facilitate the analysis. The finite element model was formed by applying geometrical characteristics, mesh, material properties and supporting and loading conditions, and the geometry of frame was created by many surfaces of triangular and rectangular elements. For modeling the finite element, standard four-node elements (CQUAD 4) were used. To converge the analysis, the number of elements was selected in a way that a proper correspondence is established between the time of analysis and accuracy of the results.
The size of the selected meshes is equal to $20 \mathrm{~mm}$. The structural model is appropriate for lightweight steel for precise and reliable prediction of the response of lightweight steel frames. In this study, a classical plasticity model of existing metals in software MSC PATRAN-NASTRAN for steel modeling was used. This model uses Von Mises yield surface with depending plastic flow which makes the isotropic yield possible. Using this model, there is the possibility of defining the behavior of complete plastic or isotropic hardening behavior or kinematics; in fact, steel hardening is a combination of isotropic and kinematic (compound) behaviors.

The type of lateral behavior analysis of the walls used is nonlinear pushover analysis. In this analysis, the stressstrain relationship is nonlinear and each point of sentences having the second derivative of ductility is also considered 
in the strain calculation. So, the possibility of examining the behavior of the structure and ductility were calculated with higher accuracy.

\section{Loading and support conditions}

The cyclic loading regime that has been used in this study is based on Method B of ASTM Standard (2007), which was originally developed for ISO (International Organization for Standardization) standard 16670. This loading methodology consists of one full cycle at $0.5,1,2,3$ and $4 \mathrm{~mm}$ and three full cycles at $8,16,24,32,40,48,56,64$ and $72 \mathrm{~mm}$, unless failure or a significant decrease in the load resistance occurs earlier. The mentioned lateral amplitudes correspond to 1.55 , $3.125,6.25,9.35,12.5,25,50,75,100,125,150,175,200$ and $225 \%$ of the ultimate monotonic lateral displacement of the walls, which was evaluated to be equal to $32 \mathrm{~mm}$. It is worth noting that Method B of ASTM E2126-07 stipulates that the amplitude of cyclic displacements has to be selected based on fractions of monotonic ultimate displacement. If this was applied here, since each specimen had its own ultimate displacement, the loading regime would vary for different specimen types. However, as set out earlier, one of the current research objectives is the comparison of different types of K-braced configurations of the shear walls, which would necessitate using identical cyclic amplitudes for different walls. Hence, Method B is used in this study with lateral amplitude independent of monotonic testing. Moreover, although $75 \mathrm{~mm}$, or $3.125 \%$, the inter-story drift ratio was the maximum amplitude of the actuator and was considered to be adequate, since the maximum allowable story drift ratio specified by the Standard FEMA450 (2003) is $2.5 \%$. The average loading velocity was about $2 \mathrm{~mm} / \mathrm{s}$ which is compatible with the ASTM E2126-07 recommendation that the loading velocity must be in the range of $1-63 \mathrm{~mm} / \mathrm{s}$.

\section{Results obtained from evaluating the validation of the modeling}

The results from modeling by finite element software and laboratory work Al-Kharat and Rogers (2007)have been presented in Table 3 and Fig. 3. According to the results, a proper correspondence is observed between different parameters from numerical and experimental results of the samples. The difference less than $5 \%$ causes an increased confidence in the obtained results in the evaluation.

All failure mechanisms of braced frames that occur in the laboratory cannot be seen in a finite element modeling. Therefore, some of the mechanisms of failure (belt buckling failure mode and overall deformation of the frame) are shown in Fig. 4.

Finite element modeling of Von Mises stress distribution at the end of the operation is shown in Fig. 5. The
Table 3 Comparison of results, experimental and analytical

\begin{tabular}{llll}
\hline Behavior & \multicolumn{2}{l}{ Specimen } & \\
\cline { 2 - 4 } & Analytical & Experimental & Difference (\%) \\
\hline$S_{\mathrm{y}}(\mathrm{kN})$ & 86.23 & 82.93 & 3.8 \\
$S_{\mathrm{yp}}(\mathrm{kN})$ & 108.17 & 103.40 & 4.6 \\
$K_{\mathrm{e}}(\mathrm{kN} / \mathrm{mm})$ & 4.14 & 3.61 & 3.2 \\
$\Delta_{0.8}(\mathrm{~mm})$ & 68.47 & 71.93 & 4.7 \\
Energy $(\mathrm{kN} \mathrm{mm})$ & 5819 & 5622 & 3.4 \\
\hline
\end{tabular}

critical value of the stress field occurred at the end of the studs, which could damage the local buckling of the stud and make them unable to reach a total capacity of yield.

\section{Parametric study}

After ensuring the accuracy of the analytical model provided by experimental results, several frame samples with different brace arrangements including Chevron, cross and $\mathrm{K}$-shape bracing were modeled in finite element software. The height of all frames was assumed to be fixed $(2.44 \mathrm{~m})$ and their length variable. Each frame consists of an upper and lower track, lateral and middle studs, and steel belt braces. Sections and materials used in studs, tracks and belts were the same in all samples and their characteristics have been presented in Tables 1 and 2 .

Nine main types of frames were studied as shown in Fig. 6. Accordingly, in total, after modeling in finite element software under cyclic and monotonic loading, 68 frames were examined in this study.

\section{Discussion on results}

In this part, results of seismic parameters for each model and diagrams from cyclic and monotonic loading of each sample will be discussed. Values of $\left(R_{0}\right)$ and $\left(R_{\mathrm{d}}\right)$ were calculated according to Eqs. $(3,4)$, respectively, and finally, for each sample, the values of response modification factor were calculated using Eq. (2).

\section{Numerical analysis of frame of samples A}

Under monotonic loading, the mean value of yielding capacity for these walls was equal to $6.07 \mathrm{kN}$ that is equivalent to $78.36 \%$ of the value of the predicted yielding capacity. Under cyclic loading, the mean yielding resistance was obtained as $6.29 \mathrm{kN}$ and the ratio of $\left(S_{\mathrm{y}} / S_{\mathrm{yp}}\right)$ was equal to $79.13 \%$. For monotonic and cyclic tests, the mean value of $\Delta_{0.8}$ was assessed as 119.83 and 124.91, respectively, and the mean value of ductility was equal to 4.39 and 4.97 , respectively (Table 4). 
Fig. 3 Comparison of results, experimental and analytical
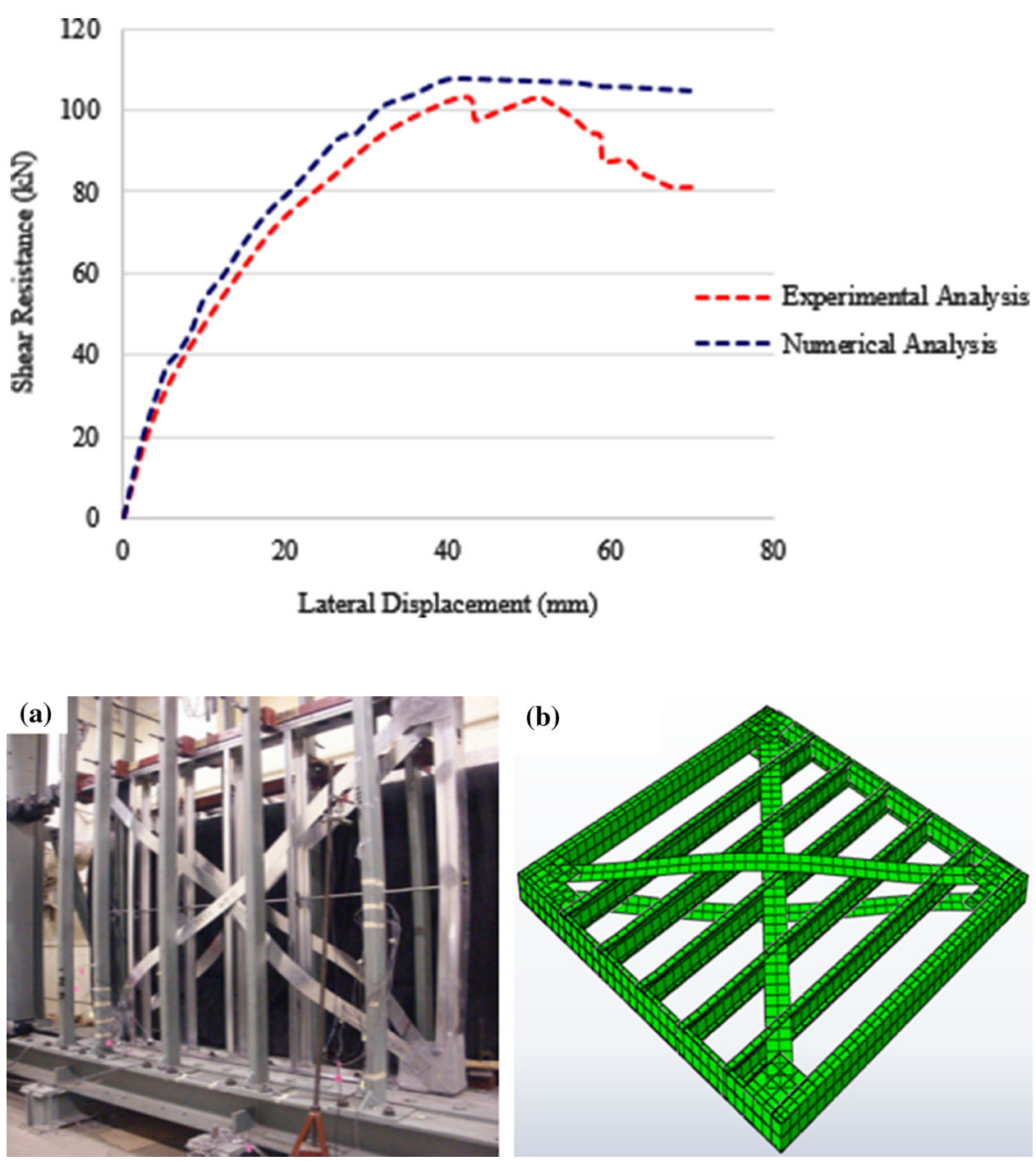

Fig. 4 Overall deformation of the frame: a experimental model, $\mathbf{b}$ analytical model (FEM)
To calculate $\left(R_{\mathrm{d}}\right)$ from Eq. (3) for wall without brace, a value of mean ductility equal to 4.67 was used and the value of $R_{\mathrm{d}}$ was evaluated as 2.89 for walls without brace (Table 9). Since the value of $\left(S_{\mathrm{y}} / S_{\mathrm{yp}}\right)$ is less than 1 , there is no additional resistance; thus the value of $\left(R_{0}\right)$ is considered equal to 1 . Finally, the value of the response modification factor was obtained as 2.89 (Fig. 7).

By increasing the rate of height to length of wall, elastic stiffness and stiffness values are expected to increase and the amount of plasticity decreased. Using double straps will improve strength, stiffness and ductility.

\section{Numerical analysis of frames of samples B}

The mean value of yielding capacity under monotonic loading of sample B with lateral and bilateral braces was obtained as 106.64 and $169.53 \mathrm{kN}$, respectively, which has been predicted as being equivalent to 73.85 and $75.50 \%$ of the capacity values (Tables 5,6 ). The mean value of yielding capacity under cyclic loading of samples B with lateral and bilateral braces was obtained as 114.80 and $183.58 \mathrm{kN}$, respectively, and also the ratio of $\left(S_{\mathrm{y}} / S_{\mathrm{yp}}\right)$ was obtained as 73.24 and $135.91 \%$, respectively (Tables 7, 8). The value of the yielding capacity of bilateral brace was around $60 \%$ more than that of the lateral brace. Sample B with a lateral brace could not get the total of predicted yielding capacity and, at the moment of wall failure, the brace did not reach the total of its yielding capacity; however, the status of bilateral brace sample has somewhat improved compared to that of lateral brace sample and it could get the total of predicted capacity under cyclic loading.

For the ratio of yielding capacity to the nominal yielding capacity, the mean value was 101.56 and $161.64 \%$, respectively (Tables 5, 6), under monotonic loading of these samples with lateral and bilateral braces and 109.33 and 
Fig. 5 Von Mises stress distribution (FEM)

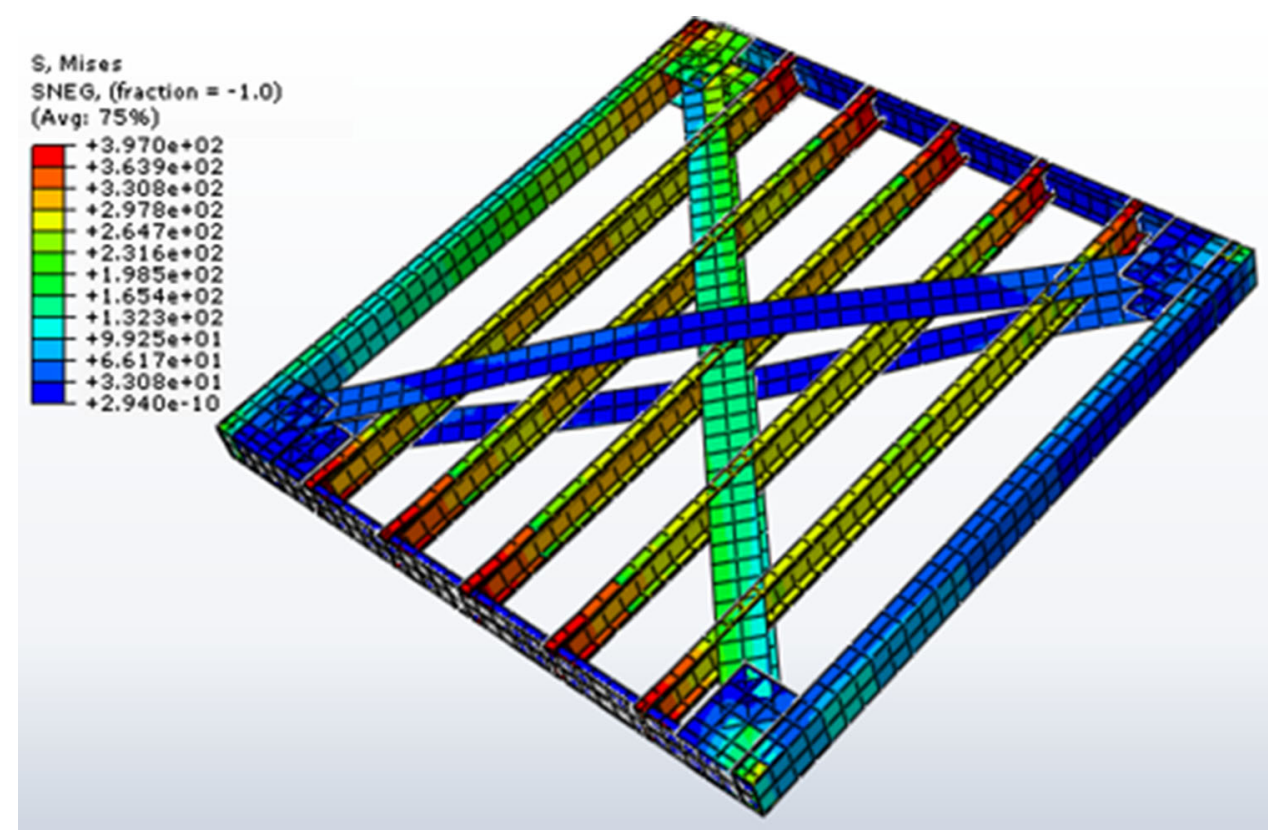

$174.84 \%$, respectively, (Tables 7,8 ) under cyclic loading. These values show that sample B with lateral and bilateral brace could get the expected nominal design shear resistance well.

The mean value of $\left(\Delta_{0.8}\right)$ was evaluated as 45.51 and $43.24 \mathrm{~mm}$, respectively (Tables 5,6 ), under monotonic loading of samples B with lateral and bilateral braces and 44.41 and $42.93 \mathrm{~mm}$, respectively (Tables 7, 8), under cyclic loading. The presence of bilateral brace on the wall causes about $4 \%$ reduction in its maximum displacement compared to lateral brace samples. The mean value of ductility was evaluated as 2.02 and 2.27 , respectively (Tables 5, 6), under monotonic loading of samples B with lateral and bilateral braces and 2.14 and 2.23 , respectively (Tables 7,8$)$ under cyclic loading. To calculate $\left(R_{\mathrm{d}}\right)$ from Eq. (3) for wall with lateral brace, a mean value of ductility equal to 2.08 was used and the value of $R_{\mathrm{d}}$ was evaluated as 1.78. The mean value of additional resistance $\left(R_{0}\right)$ was equal to 1.05 for wall with lateral brace and, finally, the value of the response modification factor was obtained as 1.87 (Table 9). To calculate the value of $\left(R_{\mathrm{d}}\right)$ for wall with bilateral brace, a mean value of ductility equal to 2.25 was used and the value of $R_{\mathrm{d}}$ was evaluated equal to 1.87 . Based on values of $\left(S_{\mathrm{y}} / S_{\mathrm{yp}}\right)$, the mean value of additional resistance $\left(R_{0}\right)$ was equal to 1.68 for wall with bilateral brace and, finally, the value of the response modification factor was obtained as 3.14 for sample B with bilateral brace (Table 9). If the bilateral brace is used for sample B, the value of the response modification factor will be about $66 \%$ more than that of the lateral brace.

By increasing the rate of height to length of the wall, elastic stiffness and stiffness values are expected to increase and the amount of plasticity decreased. Using double straps will improve strength, stiffness and ductility.

The value of predicted stiffness was obtained as 19.62 and $37.56 \mathrm{kN} / \mathrm{mm}$, respectively, for samples B with lateral and bilateral braces under monotonic loading (Tables 5, 6) and 42.95 and $45.69 \mathrm{kN} / \mathrm{mm}$, respectively, under cyclic loading (Tables 7, 8). Obviously, the value of $\left(K_{\mathrm{e}}\right)$ is considerably less than $\left(K_{\mathrm{p}}\right)$. The shear resistance is increased by increasing the ratio of the height to length of the wall. On the other hand, the shear wall resistance of the bilateral brace was significantly more than that of the lateral brace. This has been clearly shown in Fig. 8a-c.

\section{Numerical analysis of frames of samples C}

The mean value of yielding capacity under monotonic loading of samples $\mathrm{C}$ with lateral and bilateral braces was obtained as 118.41 and $180.14 \mathrm{kN}$, respectively, which has been predicted as equivalent to 74.85 and $75.76 \%$ of the capacity values (Tables 5,6 ). The mean value of yielding capacity under cyclic loading of samples $\mathrm{C}$ with lateral and bilateral braces was obtained as 125.35 and $191.59 \mathrm{kN}$, respectively, and also the ratio of $\left(S_{\mathrm{y}} / S_{\mathrm{yp}}\right)$ was obtained as 74.22 and $137.16 \%$, respectively (Tables 7,8 ). The value of the yielding capacity of the bilateral brace was around $52 \%$ more than that of the lateral brace. Sample $\mathrm{C}$ with a lateral brace could not get the total of predicted yielding capacity and at the moment of wall failure, braces did not reach the total of the yielding capacity; however, the status of bilateral brace sample has somewhat improved compared to that of the lateral brace sample and could obtain the total of the predicted capacity under cyclic loading. For 
Fig. 6 General configuration of specimens

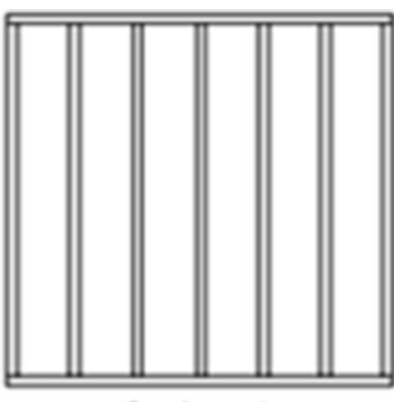

Specimen A

(a)

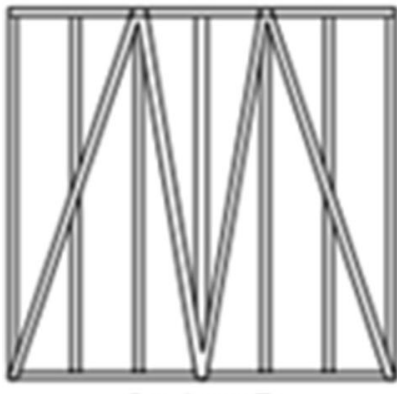

Specimen D

(d)

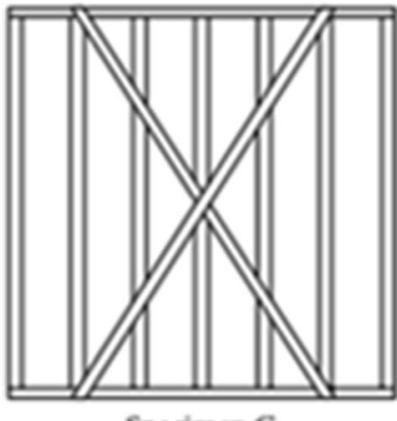

Specimen G

(g)

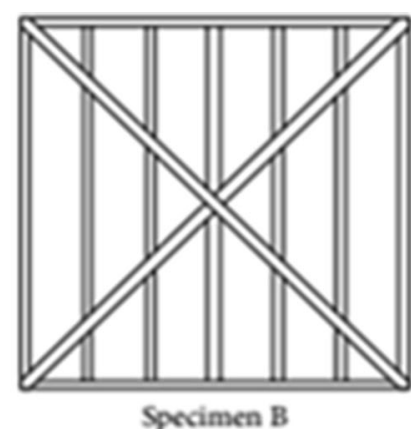

(b)

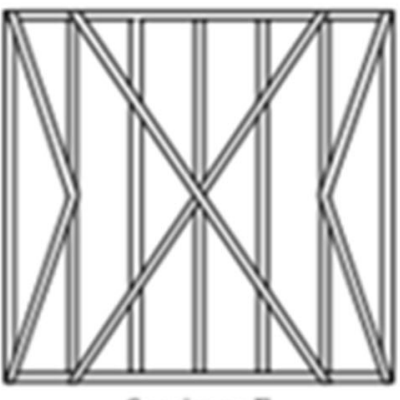

Specimen E

(e)

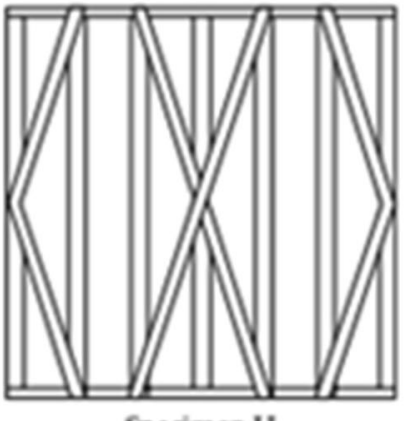

Specimen H

(h)

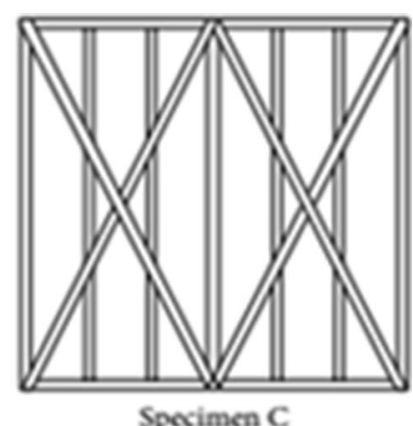

(c)

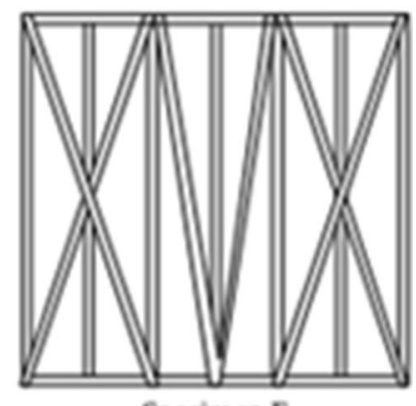

Specimen F

(f)

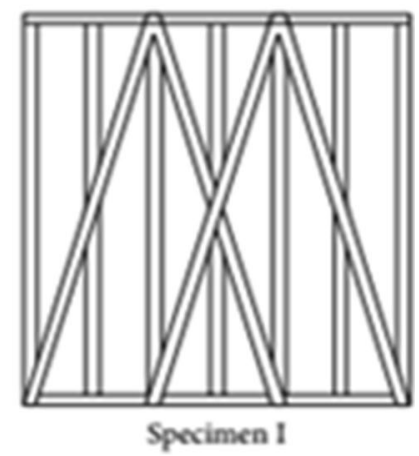

(i) the ratio of yielding capacity to the nominal yielding capacity, the mean value was 112.77 and $171.56 \%$, respectively (Tables 5, 6), under monotonic loading of these samples with lateral and bilateral braces and 119.38 and $182.47 \%$, respectively (Tables 7,8 ), under cyclic loading. These values show that sample $C$ with lateral and bilateral brace could get the expected nominal design shear resistance well.

The mean value of $\left(\Delta_{0.8}\right)$ was evaluated as 37.14 and $36.89 \mathrm{~mm}$, respectively (Tables 5,6 ), under monotonic loading of samples $\mathrm{C}$ with lateral and bilateral braces and 35.78 and $34.59 \mathrm{~mm}$, respectively (Tables 7, 8), under cyclic loading. The presence of bilateral brace on the wall causes about $2 \%$ reduction on its maximum displacement compared to lateral brace samples. The mean value of ductility was evaluated as 1.72 and 2.03 , respectively
(Tables 5, 6), under monotonic loading of samples $\mathrm{C}$ with lateral and bilateral braces and 1.82 and 1.89 , respectively (Tables 7,8$)$, under cyclic loading. To calculate $\left(R_{\mathrm{d}}\right)$ from Eq. (3) for wall with lateral brace, a mean value of ductility equal to 1.77 was used and the value of $R_{\mathrm{d}}$ was evaluated as 1.59. The mean value of additional resistance $\left(R_{0}\right)$ was equal to 1.16 for wall with lateral brace and, finally, the value of the response modification factor was obtained as 1.85 (Table 9). To calculate the value of $\left(R_{\mathrm{d}}\right)$ for wall with bilateral brace, a mean value of ductility equal to 1.96 was used and the value of $R_{\mathrm{d}}$ was evaluated equal to 1.71 . Based on values of $\left(S_{\mathrm{y}} / S_{\mathrm{yp}}\right)$, the mean value of additional resistance $\left(R_{0}\right)$ was equal to 1.77 for wall with bilateral brace and, finally, the value of the response modification factor was obtained as 3.02 for sample $\mathrm{C}$ with bilateral brace (Table 9). If the bilateral brace is used for sample C, 


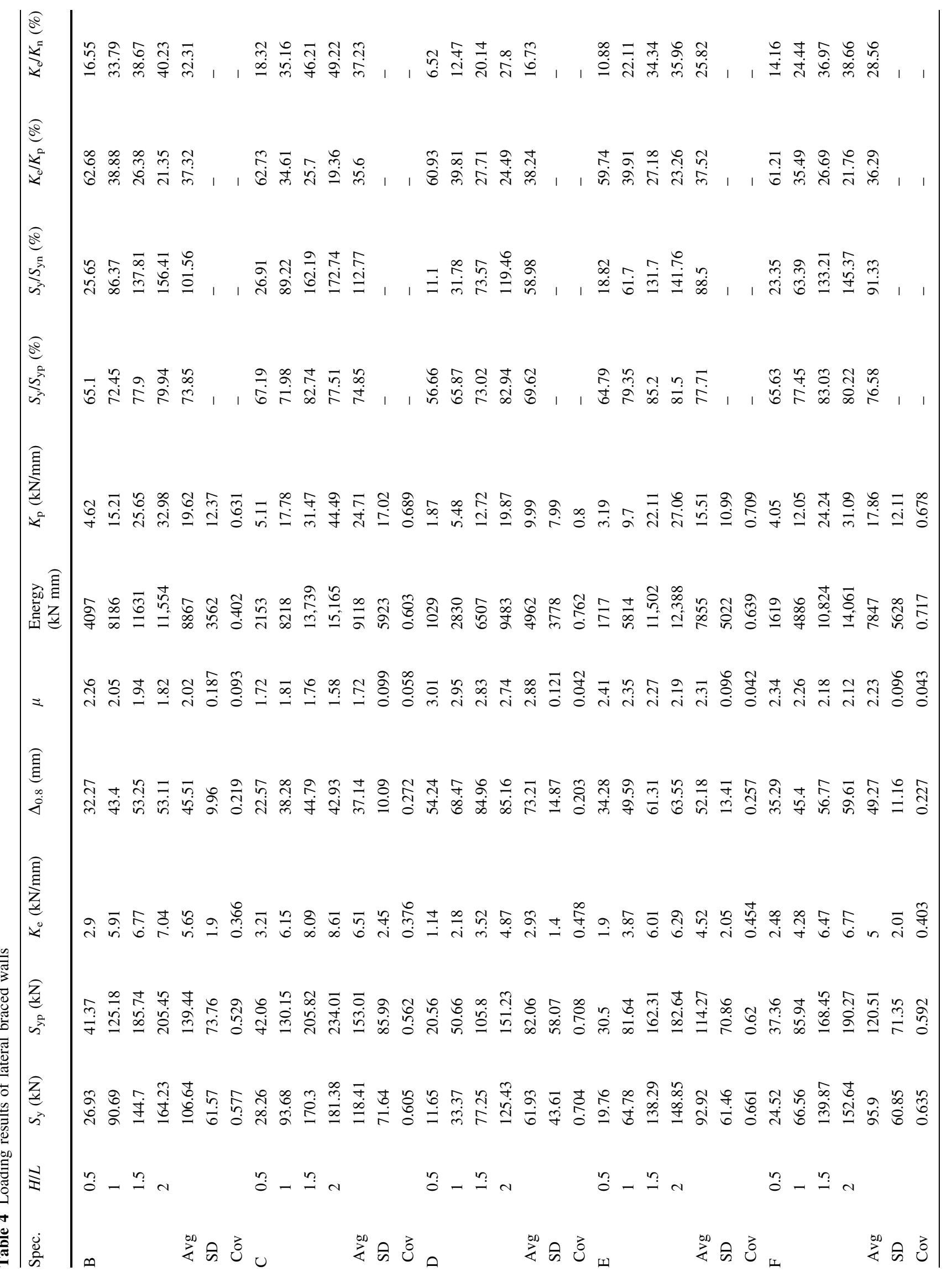


192

Int J Adv Struct Eng (2015) 7:181-209

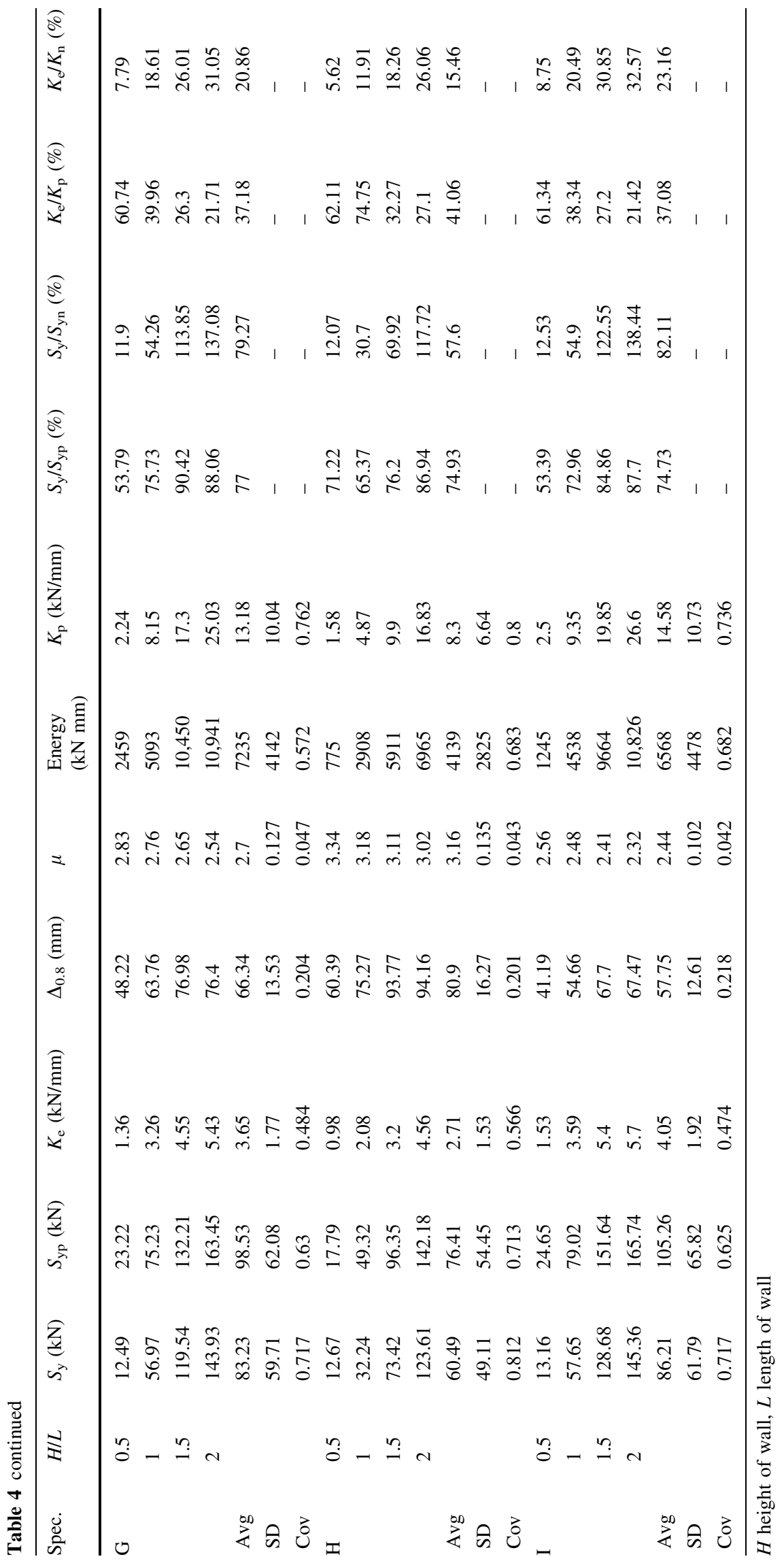

Springer 
Fig. 7 Curves of specimens A. a Monotonic curves.

b Hysteretic envelope curve (a)

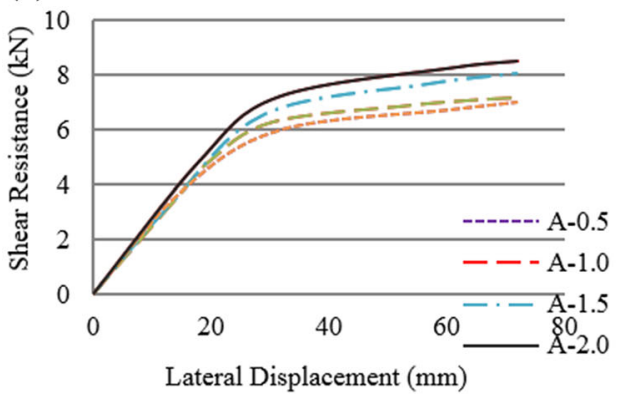

(b)

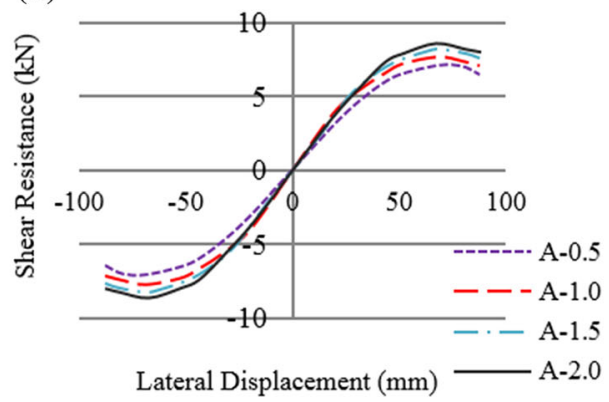

the value of the response modification factor will be about $63 \%$ more than that of the lateral brace.

The value of predicted stiffness was obtained as 24.71 and $45.36 \mathrm{kN} / \mathrm{mm}$, respectively, for samples $C$ with lateral and bilateral braces under monotonic loading (Tables 5,6) and 42.46 and $45.18 \mathrm{kN} / \mathrm{mm}$, respectively under cyclic loading (Tables 7, 8). Obviously, the value of $\left(K_{\mathrm{e}}\right)$ is considerably less than $\left(K_{\mathrm{p}}\right)$. The shear resistance is increased by increasing the ratio of the height to length of the wall. On the other hand, the shear wall resistance of bilateral brace was significantly more than that of the lateral brace. This has been clearly shown in Fig. 9a-c.

\section{Numerical analysis of frames of samples D}

The mean value of yielding capacity under monotonic loading of samples D with lateral and bilateral braces was obtained as 61.93 and $87.11 \mathrm{kN}$, respectively, which has been predicted to be equivalent to 69.62 and $79.01 \%$ of capacity values (Tables 5,6 ). The mean value of yielding capacity under cyclic loading of samples D with lateral and bilateral braces was obtained as 69.13 and $96.02 \mathrm{kN}$, respectively, and also the ratio of $\left(S_{\mathrm{y}} / S_{\mathrm{yp}}\right)$ was obtained as 74.27 and $120.70 \%$, respectively (Tables 7 , 8 ). The value of the yielding capacity of bilateral brace was around $40 \%$ more than that of the lateral brace. Sample D with a lateral brace could not get the total of predicted yielding capacity and, at the moment of wall failure, braces did not reach the total of the yielding capacity; however, the status of bilateral brace sample has somewhat improved compared to that of lateral brace sample and it could get the total of predicted capacity under cyclic loading. For the ratio of yielding capacity to the nominal yielding capacity, the mean value was 58.98 and $82.96 \%$, respectively (Tables 5,6 ), under monotonic loading of these samples with lateral and bilateral braces and 65.84 and $91.44 \%$, respectively (Tables 7,8 ), under cyclic loading. These values show that samples D with lateral and bilateral brace could not get the expected nominal design shear resistance.
The mean value of $\left(\Delta_{0.8}\right)$ was evaluated as 73.21 and $55.31 \mathrm{~mm}$, respectively (Tables 5,6 ), under monotonic loading of samples D with lateral and bilateral braces and 71.49 and $69.11 \mathrm{~mm}$, respectively (Tables 7,8 ) under cyclic loading. The presence of bilateral brace on wall causes about $13.8 \%$ reduction on its maximum displacement compared to the lateral brace samples. The mean value of ductility was evaluated as 2.88 and 2.97 , respectively (Tables 5,6 ), under monotonic loading of samples D with lateral and bilateral braces and 3.06 and 3.19, respectively (Tables 7,8$)$ under cyclic loading. To calculate $\left(R_{\mathrm{d}}\right)$ from Eq. (3) for wall with lateral brace, a mean value of ductility equal to 2.97 was used and the value of $R_{\mathrm{d}}$ was evaluated as 2.22 . Since the value of $\left(S_{\mathrm{y}} / S_{\mathrm{yp}}\right)$ is less than 1 , there is no additional resistance; thus the value of $\left(R_{0}\right)$ is considered equal to 1 . Finally, the value of the response modification factor was obtained as 2.97 (Table 9). To calculate the value of $\left(R_{\mathrm{d}}\right)$ for wall with bilateral brace, a mean value of ductility equal to 3.08 was used and the value of $R_{\mathrm{d}}$ was evaluated equal to 2.27. Since the value of $\left(S_{\mathrm{y}} / S_{\mathrm{yp}}\right)$ is less than 1 , there is no additional resistance; thus the value of $\left(R_{0}\right)$ is considered equal to 1 . Finally, the value of the response modification factor was obtained as 2.27 for sample D with bilateral brace (Table 9). If the bilateral brace is used for sample $\mathrm{D}$, the value of the response modification factor will be about $2.2 \%$ more than that of lateral brace. This small difference can result from the lack of additional resistance in the samples.

The value of predicted stiffness was obtained as 9.99 and $19.37 \mathrm{kN} / \mathrm{mm}$, respectively, for sample $\mathrm{D}$ with lateral and bilateral braces under monotonic loading (Tables 5, 6) and 14.95 and $15.91 \mathrm{kN} / \mathrm{mm}$, respectively, under cyclic loading (Tables 7, 8). Obviously, the value of $\left(K_{\mathrm{e}}\right)$ is considerably less than $\left(K_{\mathrm{p}}\right)$. The shear resistance is increased by increasing the ratio of the height to length of the wall. On the other hand, the shear wall resistance of the bilateral brace was significantly more than the lateral brace. This has been clearly shown in Fig. 10a-c.

By increasing the rate of height to length of the wall, the elastic stiffness and stiffness values are expected to 


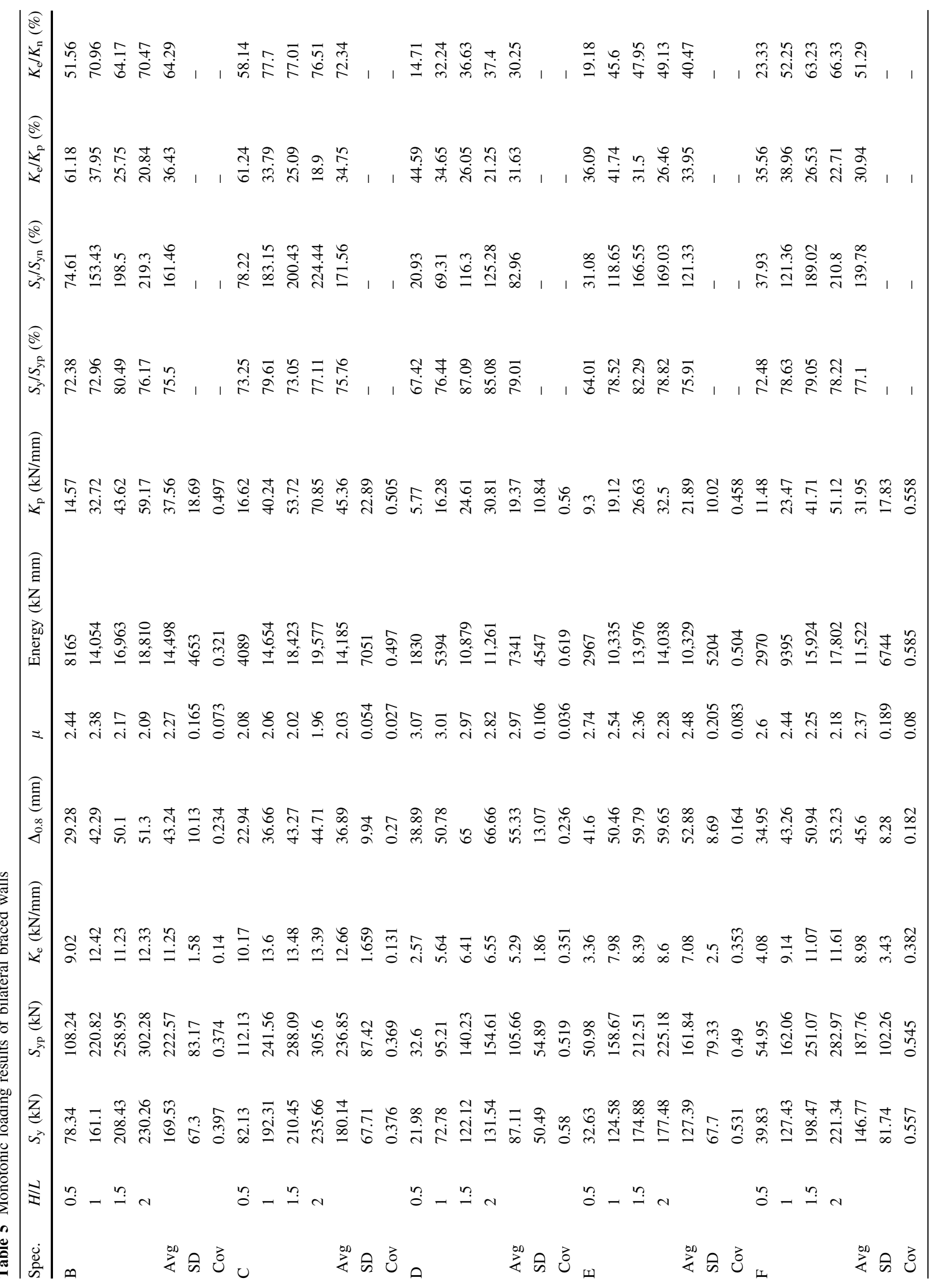




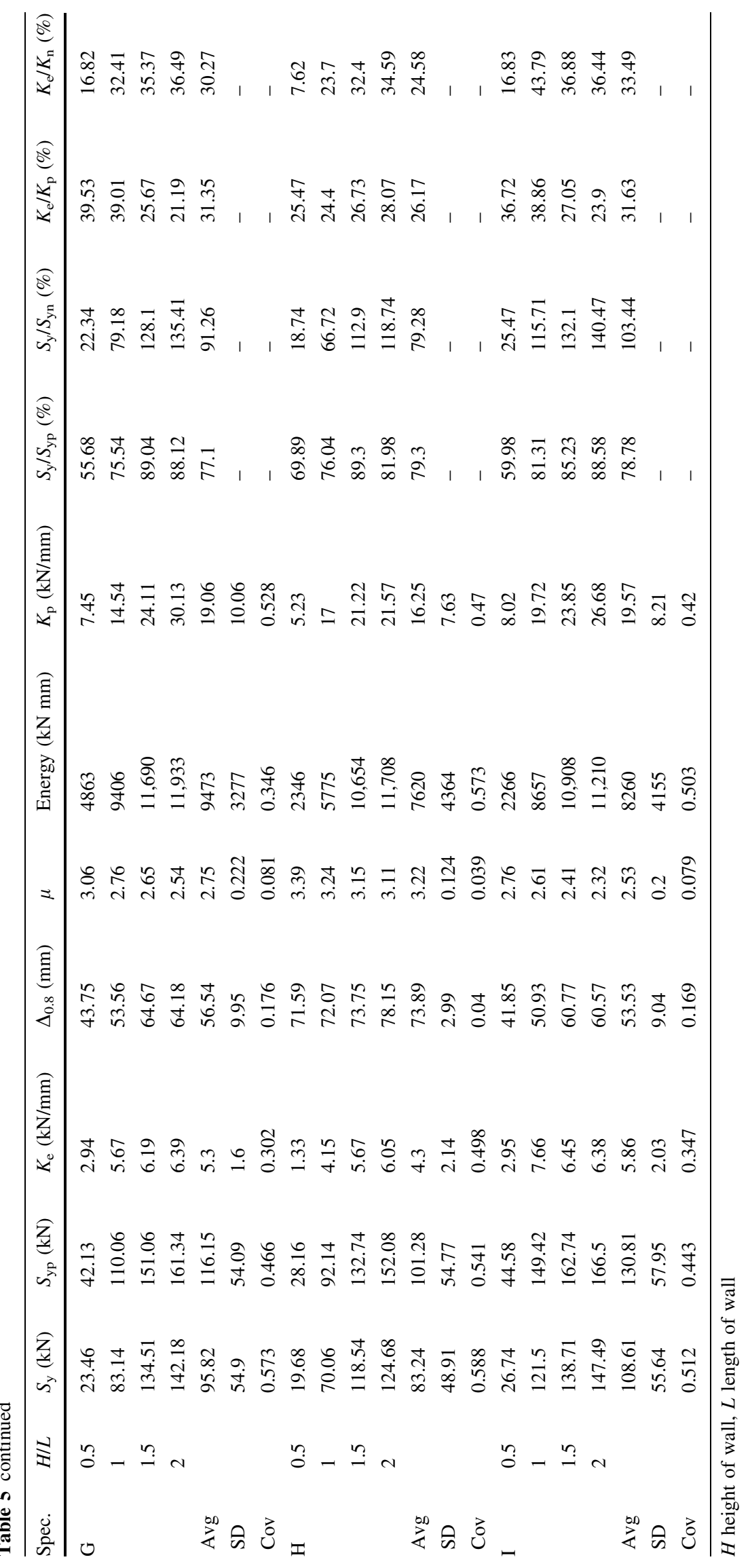




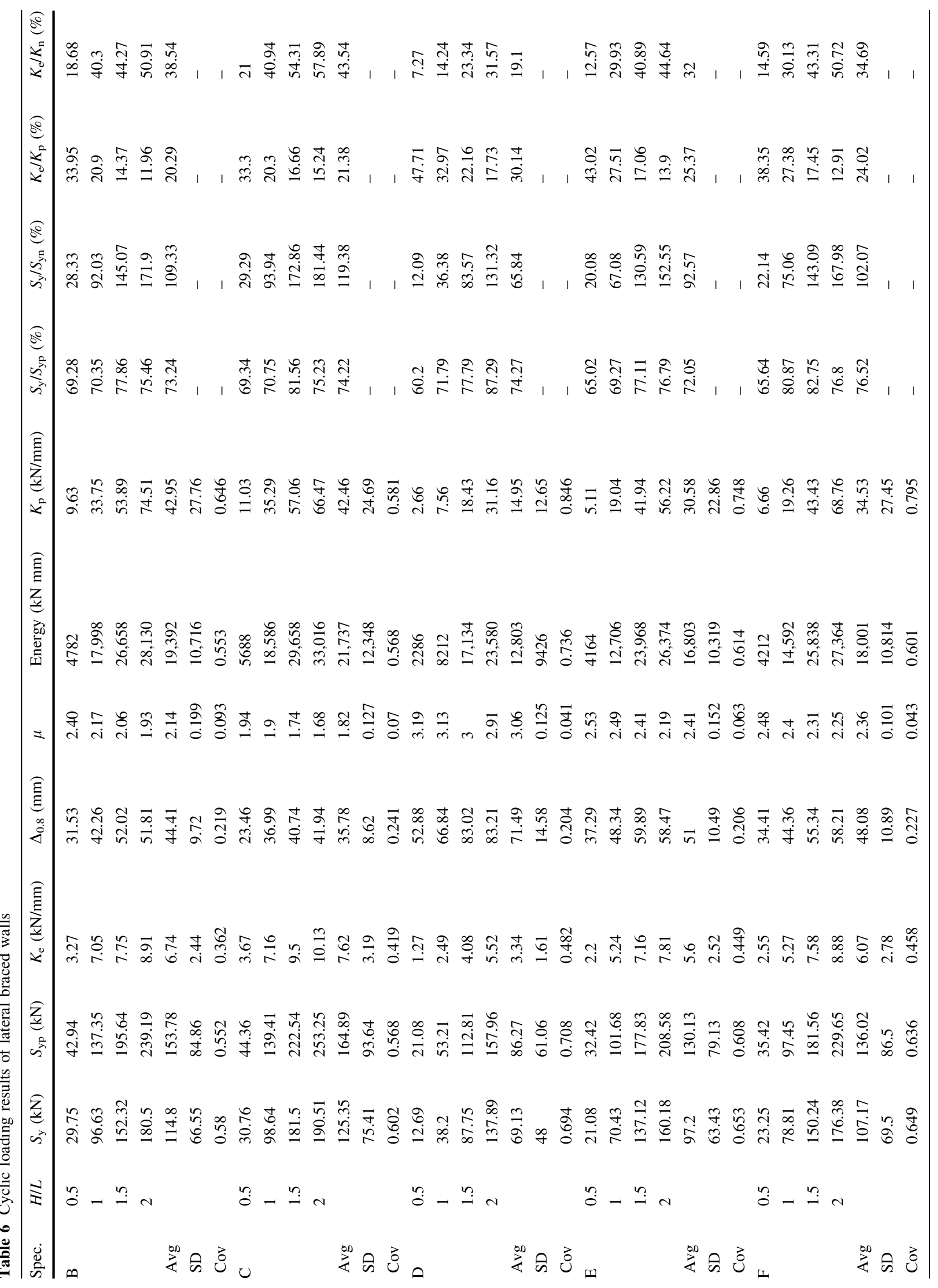




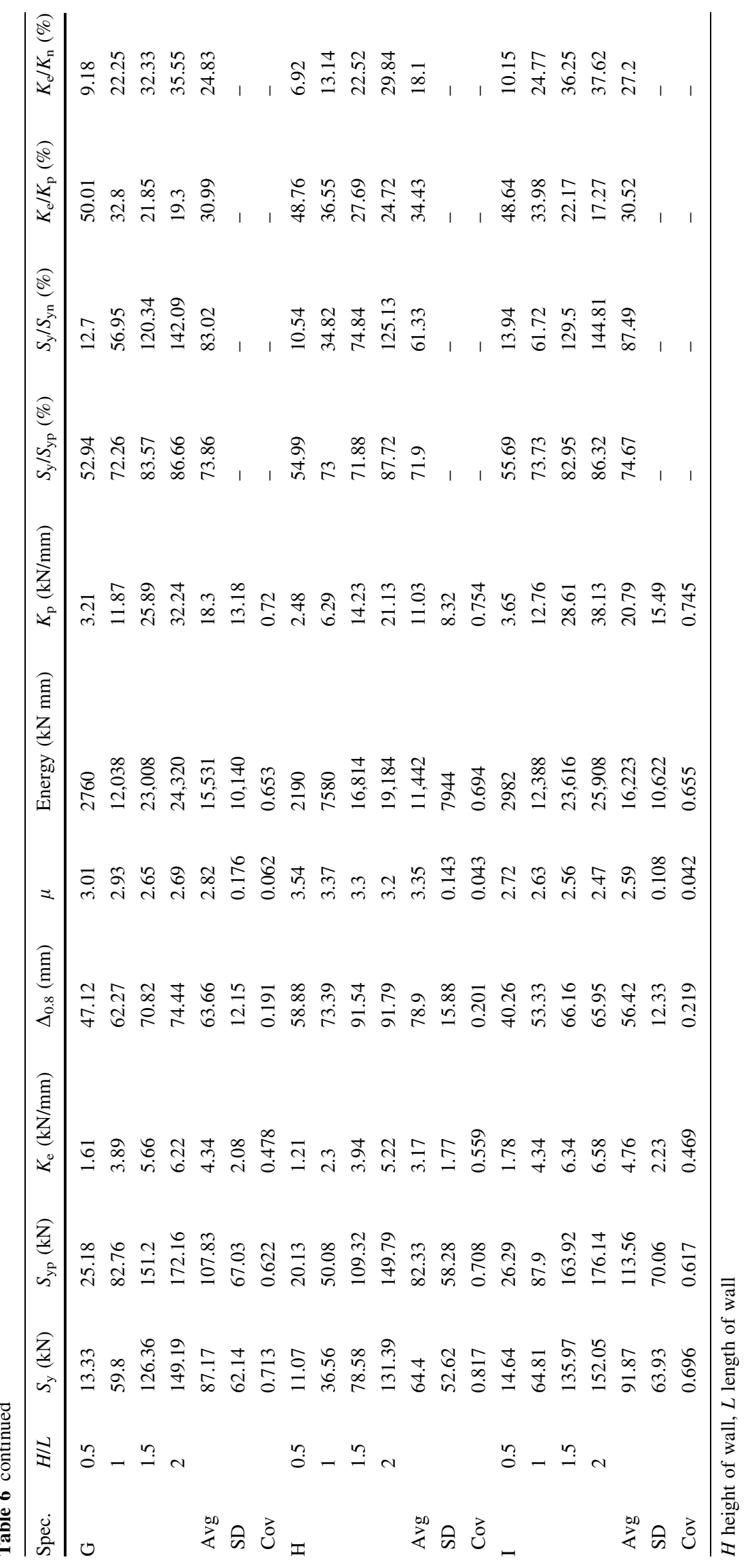




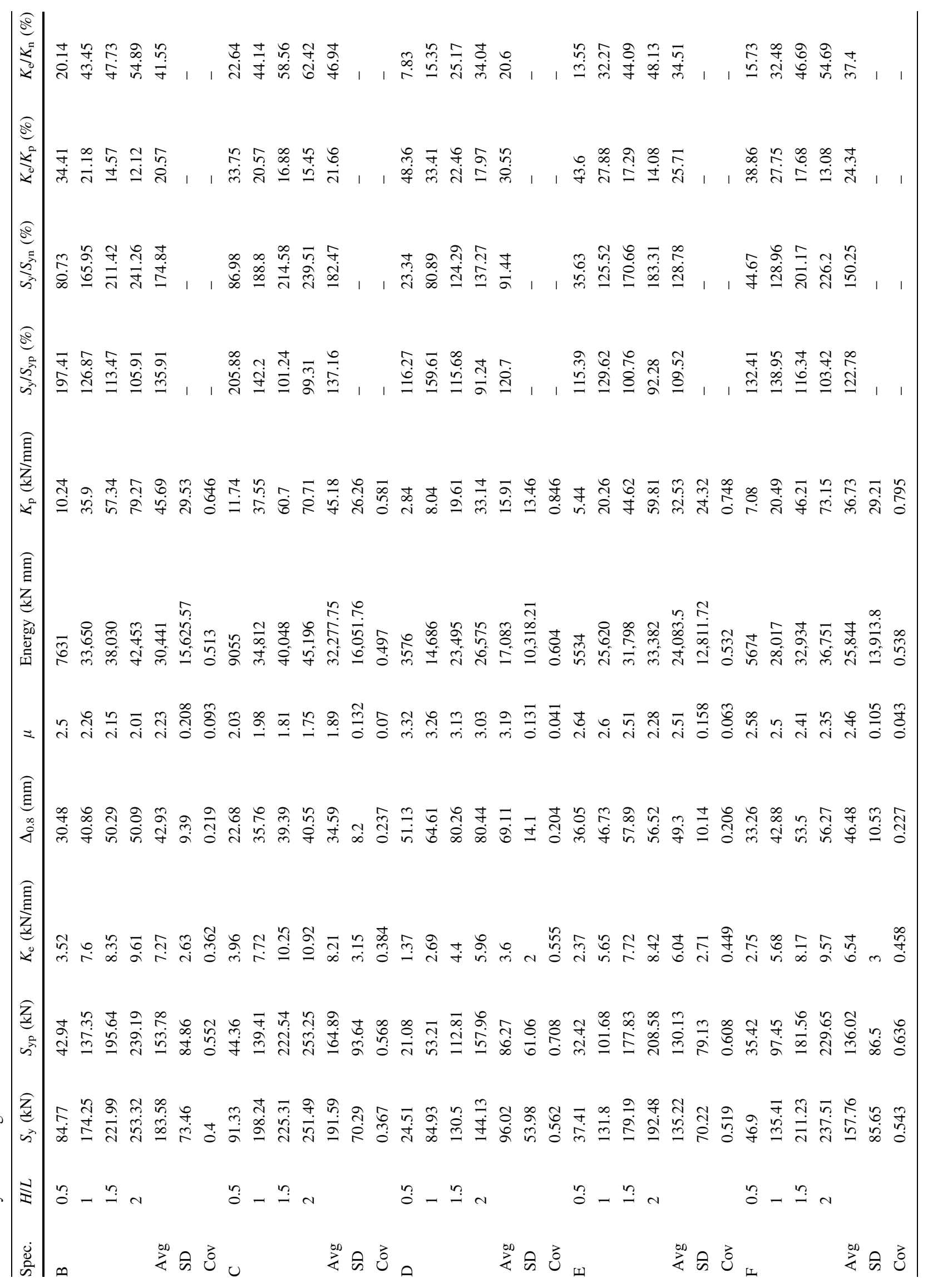




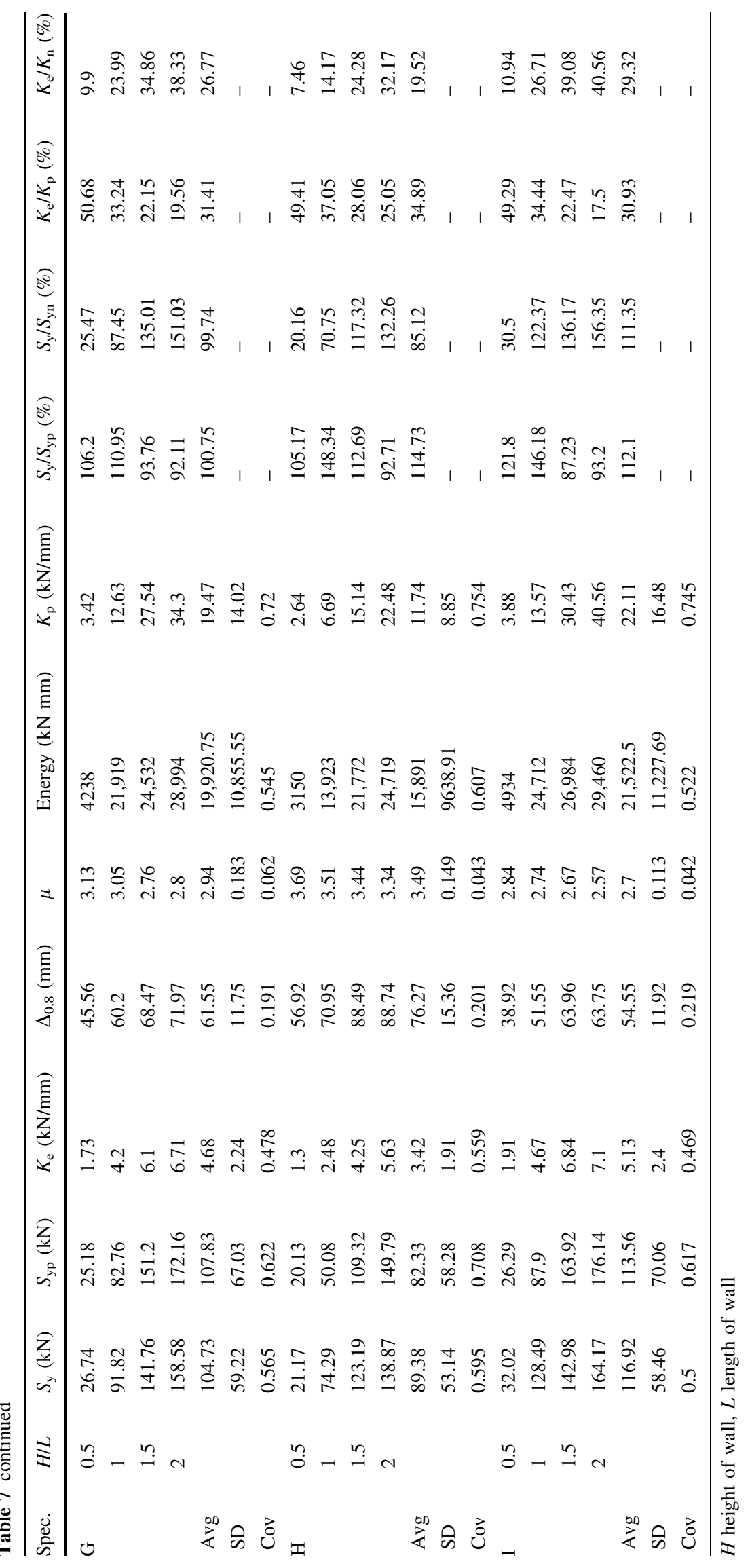


Table 8 Monotonic and cyclic loading specimens of A results

\begin{tabular}{lllllllllllccc}
\hline Spec. & $H / L$ & $S_{\mathrm{y}}(\mathrm{kN})$ & $S_{\mathrm{yp}}(\mathrm{kN})$ & $\begin{array}{l}K_{\mathrm{e}} \\
(\mathrm{kN} / \mathrm{mm})\end{array}$ & $\begin{array}{l}\Delta_{0.8} \\
(\mathrm{~mm})\end{array}$ & $\mu$ & $\begin{array}{l}\text { Energy } \\
(\mathrm{kN} \mathrm{mm})\end{array}$ & $\begin{array}{l}K_{\mathrm{p}} \\
(\mathrm{kN} / \mathrm{mm})\end{array}$ & $S_{\mathrm{y}} / S_{\mathrm{yp}}(\%)$ & $S_{\mathrm{y}} / S_{\mathrm{yn}}(\%)$ & $K_{\mathrm{e}} / K_{\mathrm{p}}(\%)$ & $K_{\mathrm{e}} / K_{\mathrm{n}}(\%)$ \\
\hline Monotonic & 0.5 & 4.92 & 7.08 & 0.28 & 114.89 & 4.57 & 145.84 & 1.08 & 69.49 & 4.69 & 26.09 \\
& 1 & 5.6 & 7.2 & 0.27 & 116.91 & 4.42 & 157.77 & 1.09 & 77.78 & 5.33 & 24.99 & 1.61 \\
& 1.5 & 6.27 & 8.13 & 0.29 & 120.12 & 4.31 & 206.23 & 1.07 & 77.12 & 5.97 & 27.38 & 1.67 \\
& 2 & 7.47 & 8.39 & 0.28 & 127.42 & 4.26 & 236.48 & 0.98 & 89.03 & 7.11 & 28.75 & 1.6 \\
Avg & & 6.07 & 7.7 & 0.28 & 119.83 & 4.39 & 186.58 & 1.05 & 78.36 & 5.78 & 26.8 & 1.61 \\
SD & & 1.09 & 0.657 & 0.008 & 5.49 & 0.137 & 42.29 & 0.052 & - & - & - & - \\
Cov & & 0.18 & 0.085 & 0.029 & 0.046 & 0.031 & 0.227 & 0.05 & - & - & - \\
Cyclic & 0.5 & 5.23 & 7.03 & 0.304 & 118.19 & 5.11 & 344 & 0.643 & 74.39 & 4.98 & 47.3 & - \\
& 1 & 5.84 & 7.56 & 0.311 & 122.16 & 5.02 & 376 & 0.753 & 77.25 & 5.56 & 41.26 & 1.74 \\
& 1.5 & 6.24 & 8.45 & 0.33 & 126.66 & 4.94 & 494 & 0.894 & 75.98 & 6.11 & 36.86 & 1.88 \\
Avg & 2 & 7.68 & 8.64 & 0.314 & 132.63 & 4.82 & 568 & 0.938 & 88.89 & 7.31 & 33.47 & 1.79 \\
SD & & 6.29 & 7.92 & 0.315 & 124.91 & 4.97 & 445.5 & 0.807 & 79.13 & 5.99 & 39.72 & 1.8 \\
Cov & & 1.04 & 0.757 & 0.011 & 6.2 & 0.123 & 104.07 & 0.135 & - & - & -
\end{tabular}

$H$ height of wall, $L$ length of wall

increase and the amount of plasticity decreased. Using double straps will improve strength, stiffness and ductility.

\section{Numerical analysis of frames of samples $E$}

The mean value of yielding capacity under monotonic loading of samples $\mathrm{E}$ with lateral and bilateral braces was obtained as 92.92 and $127.39 \mathrm{kN}$, respectively, which has been predicted equivalent to 77.71 and $75.91 \%$ of the capacity values (Tables 5,6 ). The mean value of yielding capacity under cyclic loading of samples $\mathrm{E}$ with lateral and bilateral braces was obtained as 97.20 and $135.22 \mathrm{kN}$, respectively, and also the ratio of $\left(S_{\mathrm{y}} / S_{\mathrm{yp}}\right)$ was obtained as 72.05 and $109.52 \%$, respectively (Tables 7,8 ). The value of the yielding capacity of bilateral brace was around $38 \%$ more than that of the lateral brace. Sample E with a lateral brace could not get the total of predicted yielding capacity and at the moment of wall failure, braces did not reach the total of its yielding capacity; however, the status of bilateral brace sample has somewhat improved compared to that of the lateral brace sample and it could get the total of predicted capacity under cyclic loading. For the ratio of yielding capacity to the nominal yielding capacity, the mean value was 88.50 and $121.33 \%$, respectively (Tables 5,6 ), under monotonic loading of these samples with lateral and bilateral braces and 92.57 and $128.78 \%$, respectively (Tables 7,8 ), under cyclic loading. These values show that sample $\mathrm{E}$ with bilateral brace could get the expected nominal design shear resistance well.

The mean value of $\left(\Delta_{0.8}\right)$ was evaluated as 52.18 and $52.88 \mathrm{~mm}$, respectively (Tables 5,6 ), under monotonic loading of samples $\mathrm{E}$ with lateral and bilateral braces and 51 and $49.30 \mathrm{~mm}$, respectively (Tables 7, 8), under cyclic loading. The mean value of ductility was evaluated as 2.31 and 2.48 , respectively (Tables 5,6 ), under monotonic loading of samples $\mathrm{E}$ with lateral and bilateral braces and 2.41 and 2.51 , respectively (Tables 7,8 ) under cyclic loading. To calculate $\left(R_{\mathrm{d}}\right)$ from Eq. (3) for wall with lateral brace, a mean value of ductility equal to 2.36 was used and the value of $R_{\mathrm{d}}$ was evaluated as 1.93 . Since the value of $\left(S_{\mathrm{y}} / S_{\mathrm{yp}}\right)$ is less than 1 , there is no additional resistance; thus the value of $\left(R_{0}\right)$ is considered equal to 1 . Finally, the value of the response modification factor was obtained as 1.93 (Table 9). To calculate the value of $\left(R_{\mathrm{d}}\right)$ for wall with bilateral brace, a mean value of ductility equal to 2.50 was used and the value of $R_{\mathrm{d}}$ was evaluated equal to 2 . Based on values of $\left(S_{\mathrm{y}} / S_{\mathrm{yp}}\right)$, the mean value of additional resistance $\left(R_{0}\right)$ was equal to 1.25 for wall with bilateral brace and, finally, the value of the response modification factor was obtained as 2.50 for sample $\mathrm{E}$ with bilateral brace (Table 9). If the bilateral brace is used for sample E, the value of the response modification factor will be about $29.50 \%$ more than that of lateral brace.

The value of predicted stiffness was obtained as 15.51 and $21.89 \mathrm{kN} / \mathrm{mm}$, respectively, for samples $\mathrm{E}$ with lateral and bilateral braces under monotonic loading (Tables 5,6) and 30.58 and $32.53 \mathrm{kN} / \mathrm{mm}$, respectively, under cyclic loading (Tables 7, 8). Obviously, the value of $\left(K_{\mathrm{e}}\right)$ is considerably less than $\left(K_{\mathrm{p}}\right)$. The shear resistance is increased by increasing the ratio of the height to length of the wall. On the other hand, the shear wall resistance of the bilateral brace was significantly more than the lateral brace. This has been clearly shown in Fig. 11a-c. 
Table 9 The evaluated seismic parameters

\begin{tabular}{|c|c|c|c|c|}
\hline \multirow[t]{2}{*}{ Specimen } & \multicolumn{4}{|c|}{ Behavior } \\
\hline & $\mu$ & $\mathrm{R}_{\mathrm{d}}$ & $\mathrm{R}_{\mathrm{o}}$ & $\mathrm{R}$ \\
\hline \multicolumn{5}{|l|}{ A } \\
\hline Without brace & 4.68 & 2.89 & 1 & 2.89 \\
\hline \multicolumn{5}{|l|}{ B } \\
\hline Lateral brace & 2.08 & 1.78 & 1.05 & 1.87 \\
\hline Bilateral brace & 2.25 & 1.87 & 1.68 & 3.14 \\
\hline \multicolumn{5}{|l|}{$\mathrm{C}$} \\
\hline Lateral brace & 1.77 & 1.59 & 1.16 & 1.85 \\
\hline Bilateral brace & 1.96 & 1.71 & 1.77 & 3.02 \\
\hline \multicolumn{5}{|l|}{$\mathrm{D}$} \\
\hline Lateral brace & 2.97 & 2.22 & 1 & 2.22 \\
\hline Bilateral brace & 3.08 & 2.27 & 1 & 2.27 \\
\hline \multicolumn{5}{|l|}{ E } \\
\hline Lateral brace & 2.36 & 1.93 & 1 & 1.93 \\
\hline Bilateral brace & 2.5 & 2 & 1.25 & 2.5 \\
\hline \multicolumn{5}{|l|}{$\mathrm{F}$} \\
\hline Lateral brace & 2.3 & 1.89 & 1 & 1.89 \\
\hline Bilateral brace & 2.42 & 1.96 & 1.45 & 2.84 \\
\hline \multicolumn{5}{|l|}{ G } \\
\hline Lateral brace & 2.74 & 2.13 & 1 & 2.13 \\
\hline Bilateral brace & 2.85 & 2.17 & 1 & 2.17 \\
\hline \multicolumn{5}{|l|}{$\mathrm{H}$} \\
\hline Lateral brace & 3.26 & 2.35 & 1 & 2.35 \\
\hline Bilateral brace & 3.36 & 2.39 & 1 & 2.39 \\
\hline \multicolumn{5}{|l|}{ I } \\
\hline Lateral brace & 2.52 & 2.01 & 1 & 2.01 \\
\hline Bilateral brace & 2.62 & 2.06 & 1.07 & 2.2 \\
\hline
\end{tabular}

\section{Numerical analysis of frames of samples $\mathbf{F}$}

The mean value of yielding capacity under monotonic loading of samples $\mathrm{F}$ with lateral and bilateral braces was obtained as 95.90 and $146.77 \mathrm{kN}$, respectively, which has been predicted equivalent to 76.58 and $77.10 \%$ of capacity values (Tables 5,6). The mean value of yielding capacity under cyclic loading of samples F with lateral and bilateral braces was obtained as 107.17 and $157.76 \mathrm{kN}$, respectively, and also the ratio of $\left(S_{\mathrm{y}} / S_{\mathrm{yp}}\right)$ was obtained as 76.52 and $122.78 \%$, respectively (Tables 7,8 ). The value of the yielding capacity of bilateral brace was around $50 \%$ more than that of the lateral brace. Sample F with a lateral brace could not get the total of predicted yielding capacity and, at the moment of wall failure, braces did not reach the total of the yielding capacity; however, the status of bilateral brace sample has somewhat improved compared to that of the lateral brace sample and it could get the total of predicted capacity under cyclic loading. For the ratio of yielding capacity to the nominal yielding capacity, the mean value was 91.33 and $139.78 \%$, respectively (Tables 5, 6), under monotonic loading of these samples with lateral and bilateral braces and 102.07 and $150.25 \%$, respectively (Tables 7,8), under cyclic loading. These values show that sample $\mathrm{F}$ with bilateral brace could get the expected nominal design shear resistance well.

The mean value of $\left(\Delta_{0.8}\right)$ was evaluated as 49.27 and $45.60 \mathrm{~mm}$, respectively (Tables 5, 6), under monotonic loading of samples $\mathrm{F}$ with lateral and bilateral braces and 48.08 and $46.48 \mathrm{~mm}$, respectively (Tables 7, 8), under cyclic loading. The presence of bilateral brace on wall
Fig. 8 Curves of specimens B. a Monotonic curves.

b Hysteretic envelope curves, 1-side. c Hysteretic envelope curves, 2-side

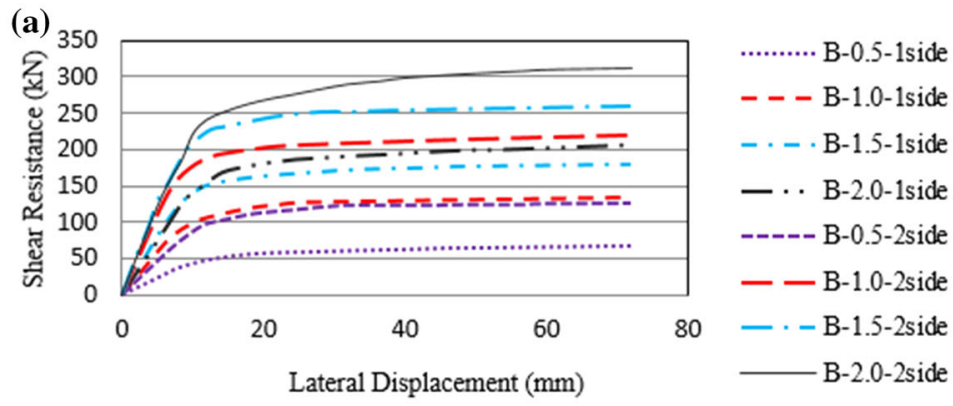

(b)

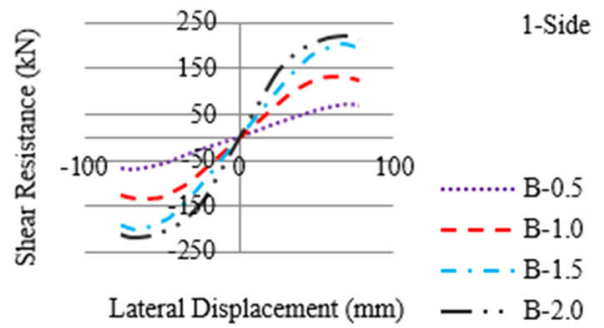

(c)

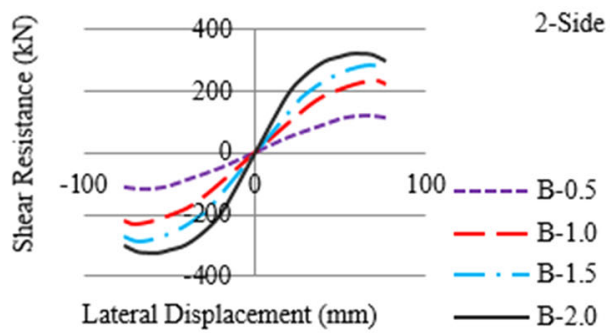


Fig. 9 Curves of specimens C. a Monotonic curves.

b Hysteretic envelope curves, 1-side. c Hysteretic envelope curves, 2-side

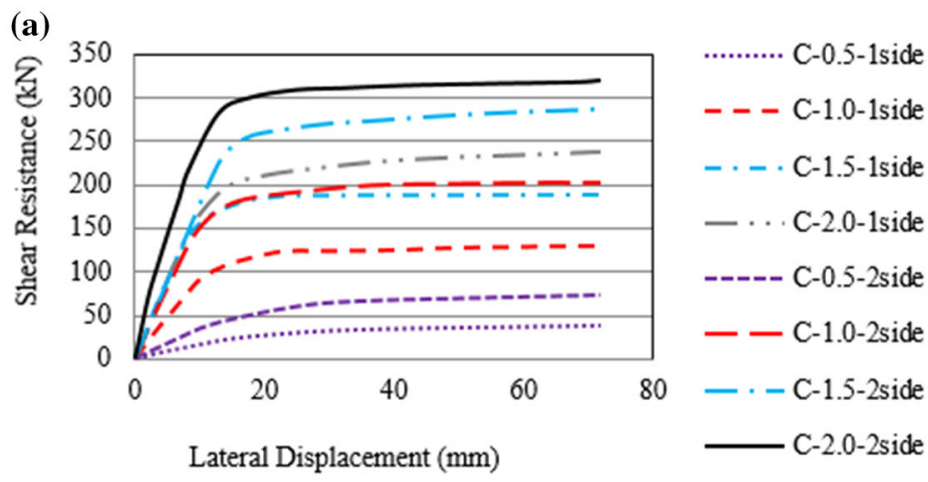

(b)

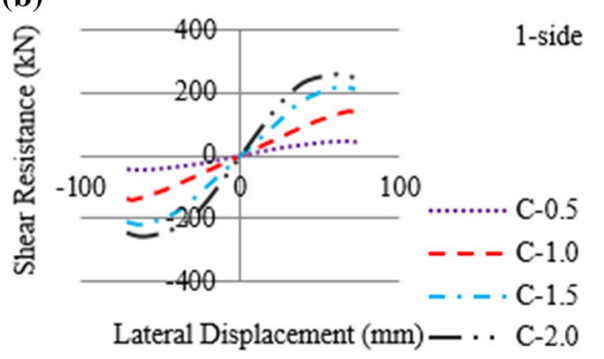

(c)

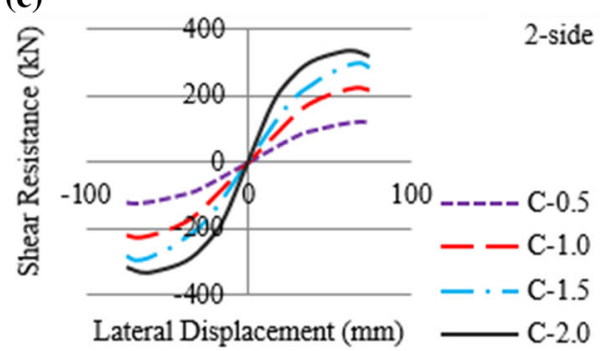

Fig. 10 Curves of specimens D. a Monotonic curves. b Hysteretic envelope curves, 1-side. c Hysteretic envelope curves, 2-side

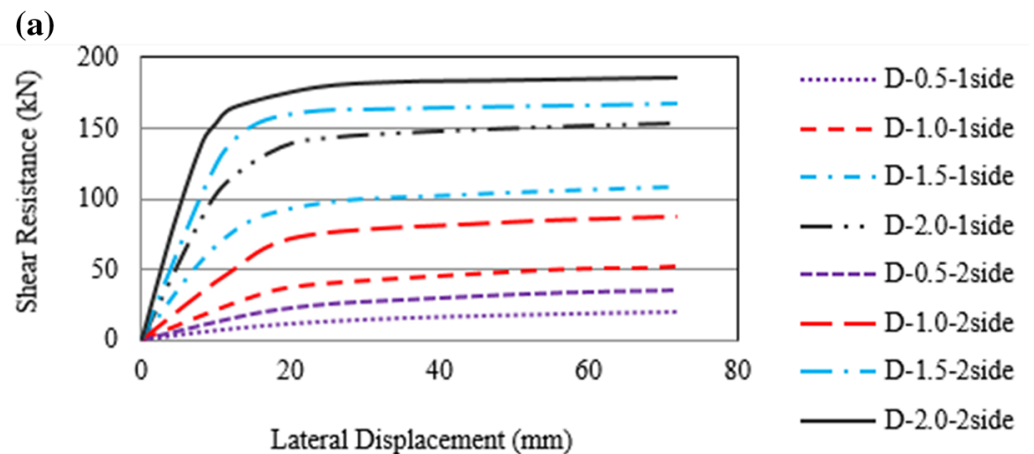

(b)

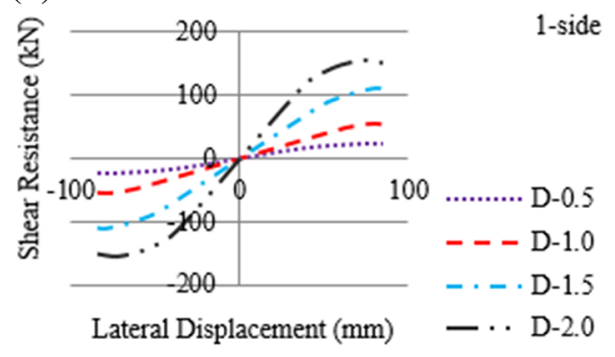

(c)

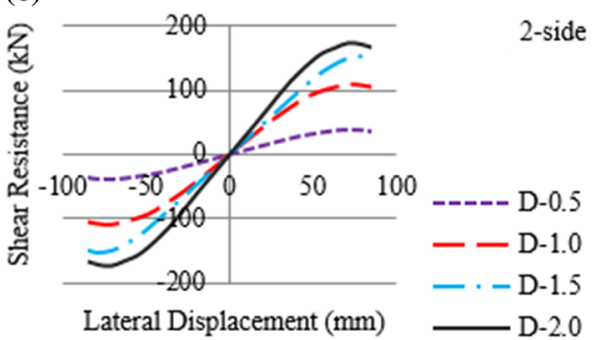

causes about $5.4 \%$ reduction on its maximum displacement compared to lateral brace samples. The mean value of ductility was evaluated as 2.23 and 2.37 , respectively (Tables 5, 6), under monotonic loading of samples $\mathrm{F}$ with lateral and bilateral braces and 2.36 and 2.46 , respectively (Tables 7,8$)$, under cyclic loading. To calculate $\left(R_{\mathrm{d}}\right)$ from Eq. (3) for wall with lateral brace a mean value of ductility equal to 2.30 was used and the value of $R_{\mathrm{d}}$ was evaluated as
1.89. Since the value of $\left(S_{\mathrm{y}} / S_{\mathrm{yp}}\right)$ is less than 1 , there is no additional resistance; thus the value of $\left(R_{0}\right)$ is considered equal to 1 . Finally, the value of the response modification factor was obtained as 1.89 (Table 9). To calculate the value of $\left(R_{\mathrm{d}}\right)$ for wall with bilateral brace, a mean value of ductility equal to 2.42 was used and the value of $R_{\mathrm{d}}$ was evaluated as equal to 1.96 . Based on values of $\left(S_{\mathrm{y}} / S_{\mathrm{yp}}\right)$, the mean value of additional resistance $\left(R_{0}\right)$ was equal to 1.45 
for wall with bilateral brace and, finally, the value of the response modification factor was obtained as 2.84 for sample $F$ with bilateral brace (Table 9). If the bilateral brace is used for sample $\mathrm{F}$, the value of the response modification factor will be about $50 \%$ more than that of the lateral brace.
The value of predicted stiffness was obtained as 17.86 and $31.95 \mathrm{kN} / \mathrm{mm}$, respectively, for samples $F$ with lateral and bilateral braces under monotonic loading (Tables 5, 6) and 34.53 and $36.73 \mathrm{kN} / \mathrm{mm}$, respectively, under cyclic loading (Tables 7, 8). Obviously, the value of $\left(K_{\mathrm{e}}\right)$ is considerably less than $\left(K_{\mathrm{p}}\right)$. The shear resistance is
Fig. 11 Curves of specimens E. a Monotonic curves. b Hysteretic envelope curves, 1-side. c Hysteretic envelope curves, 2-side
Fig. 12 Curves of specimens F. a Monotonic curves.

b Hysteretic envelope curves, 1-side. c Hysteretic envelope curves, 2-side

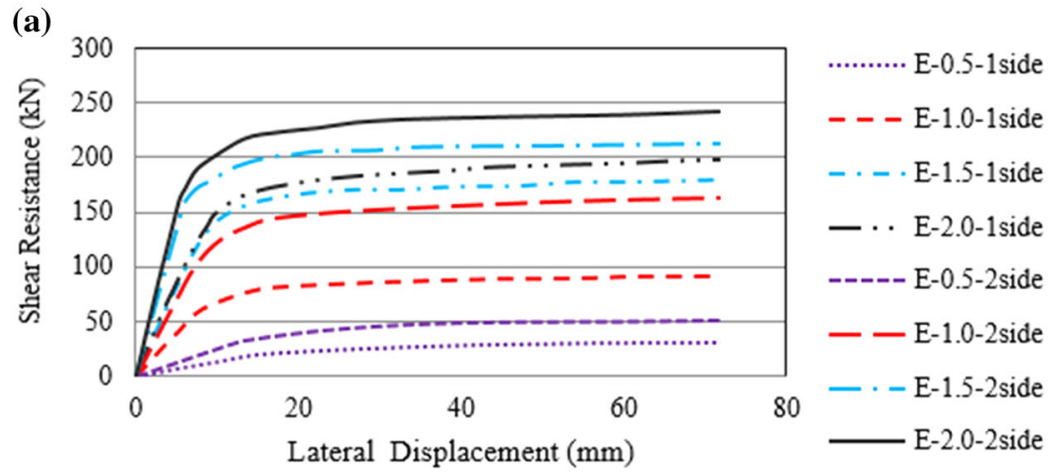

(b)

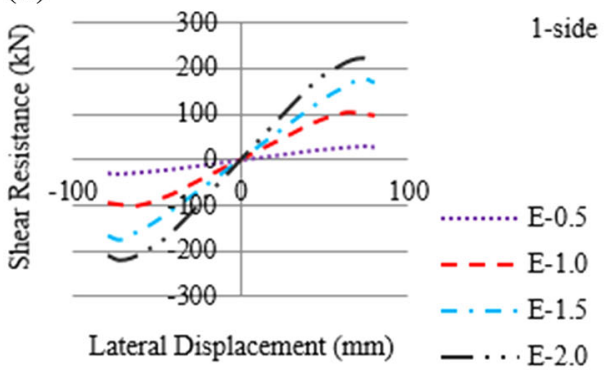

(c)

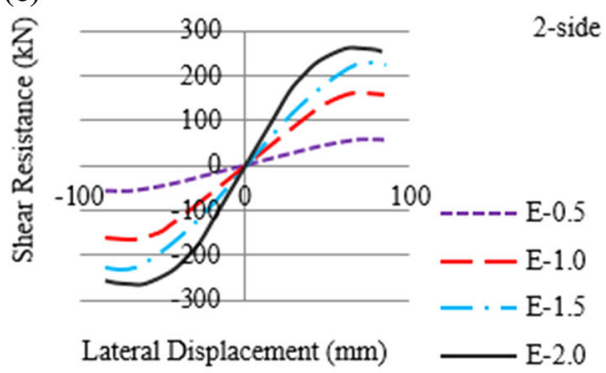

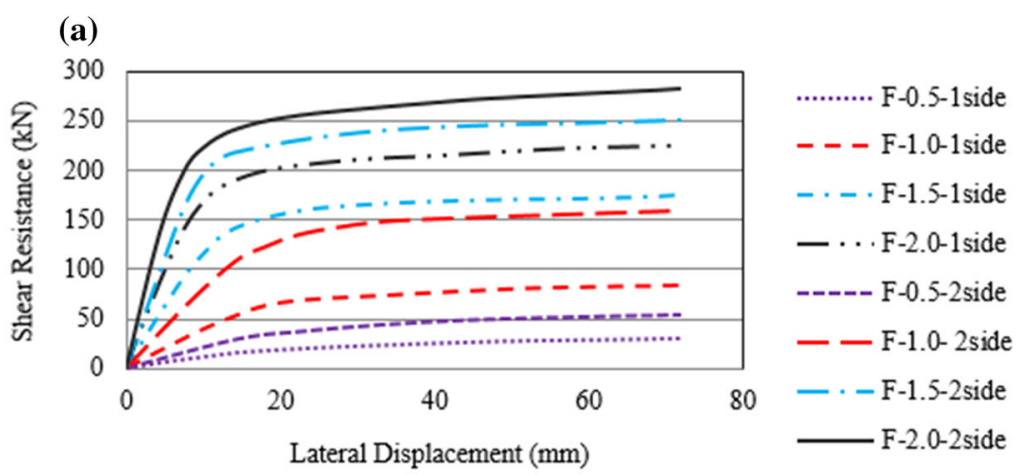

(b)

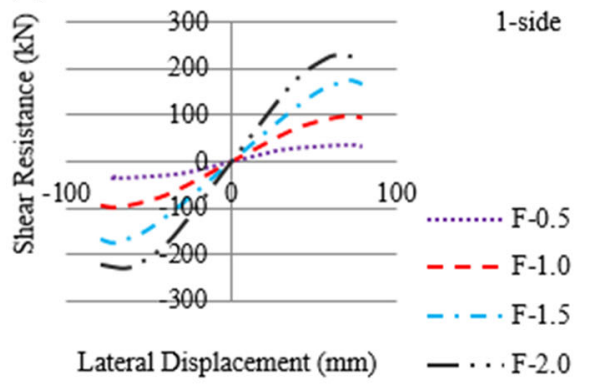

(c)

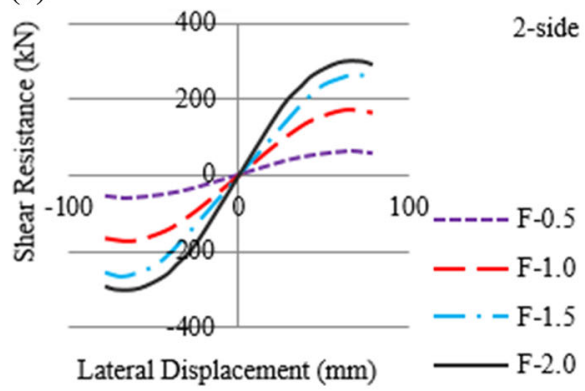


increased by increasing the ratio of the height to length of the wall. On the other hand, the shear wall resistance of bilateral brace was significantly more than that of lateral brace. This has been clearly shown in Fig. 12a-c.

\section{Numerical analysis of frames of samples G}

The mean value of yielding capacity under monotonic loading of samples $G$ with lateral and bilateral braces was obtained as 83.23 and $95.82 \mathrm{kN}$, respectively, which has been predicted to be equivalent to 77 and $77.10 \%$ of the capacity values (Tables 5,6 ). The mean value of yielding capacity under cyclic loading of samples $\mathrm{G}$ with lateral and bilateral braces was obtained as 87.17 and $104.73 \mathrm{kN}$, respectively, and also the ratio of $\left(S_{\mathrm{y}} / S_{\mathrm{yp}}\right)$ was obtained as 73.86 and $100.75 \%$, respectively (Tables 7,8 ). The value of the yielding capacity of bilateral brace is around $18 \%$ more than that of the lateral brace. Sample G with a lateral
Fig. 13 Curves of specimens G. a Monotonic curves. b Hysteretic envelope curves, 1-side. c Hysteretic envelope curves, 2-side
Fig. 14 Curves of specimens H. a Monotonic curves. b Hysteretic envelope curves, 1-side. c Hysteretic envelope curves, 2-side
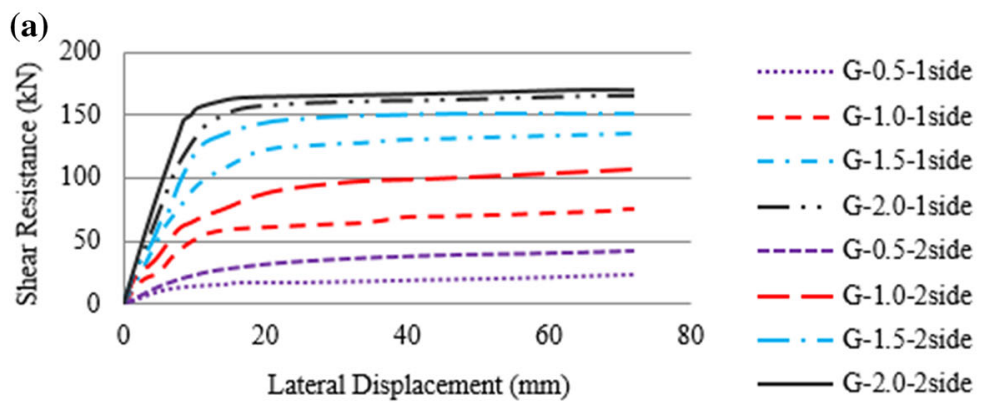

(b)

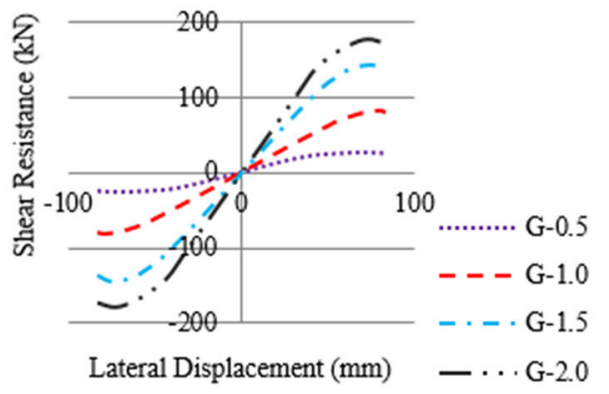

(c)

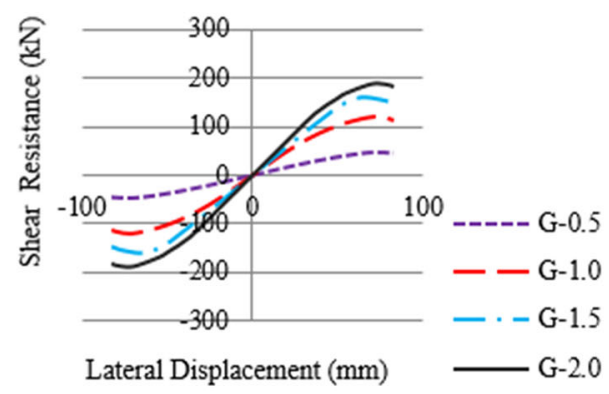

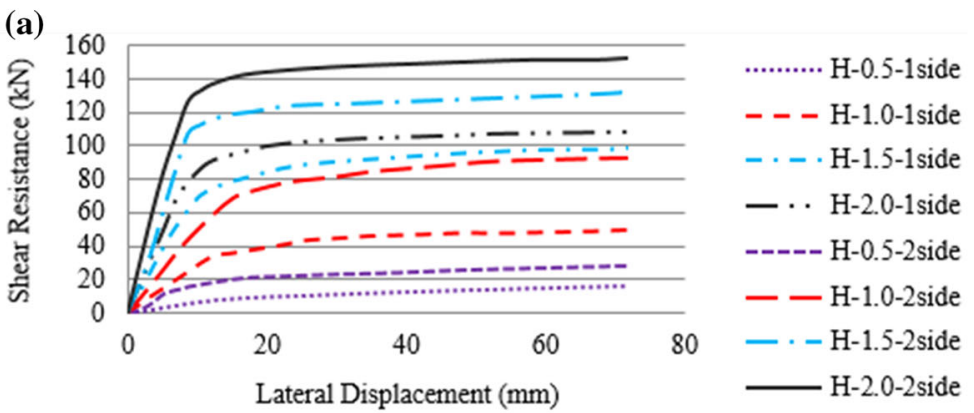

(b)

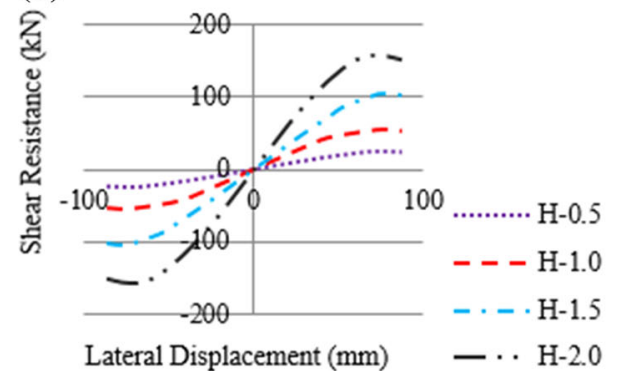

(c)

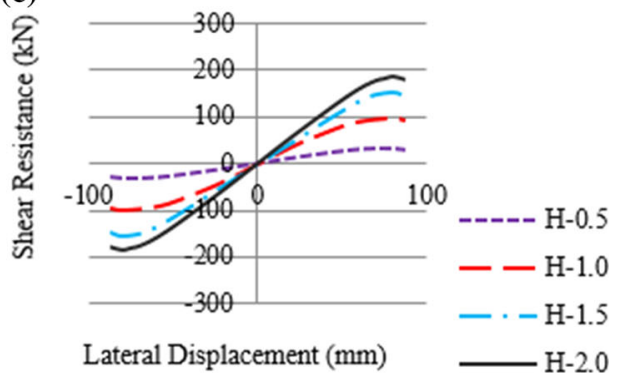


brace could not get the total of predicted yielding capacity and, at the moment of wall failure, braces did not reach the total of the yielding capacity; however, the status of bilateral brace sample has somewhat improved compared to that of the lateral brace sample and it could get the total of predicted capacity under cyclic loading. For the ratio of yielding capacity to the nominal yielding capacity, the mean value was 79.27 and $91.26 \%$, respectively (Tables 5, $6)$, under monotonic loading of these samples with lateral and bilateral braces and 83.02 and $99.74 \%$, respectively (Tables 7,8), under cyclic loading. These values show that samples $\mathrm{G}$ with lateral and bilateral brace could not get the expected nominal design shear resistance.

The mean value of $\left(\Delta_{0.8}\right)$ was evaluated as 66.34 and $56.54 \mathrm{~mm}$, respectively (Tables 5,6 ), under monotonic loading of samples $\mathrm{G}$ with lateral and bilateral braces and 63.66 and $61.55 \mathrm{~mm}$, respectively (Tables 7,8 ), under cyclic loading. The presence of bilateral brace on wall causes about $9 \%$ reduction on its maximum displacement compared to lateral brace samples. The mean value of ductility was evaluated as 2.70 and 2.75 , respectively (Tables 5, 6), under monotonic loading of samples G with lateral and bilateral braces and 2.82 and 2.94, respectively (Tables 7,8 ), under cyclic loading. To calculate $\left(R_{\mathrm{d}}\right)$ from Eq. (3) for wall with lateral brace, a mean value of ductility equal to 2.76 was used and the value of $R_{\mathrm{d}}$ was evaluated as 2.13 . Since the value of $\left(S_{\mathrm{y}} / S_{\mathrm{yp}}\right)$ is less than 1 , there is no additional resistance; thus the value of $\left(R_{0}\right)$ is considered equal to 1 . Finally, the value of the response modification factor was obtained as 2.13
Fig. 15 Curves of specimens I. a Monotonic curves.

b Hysteretic envelope curves, 1-side. c Hysteretic envelope curves, 2-side
Fig. 16 Comparing values of response modification factors

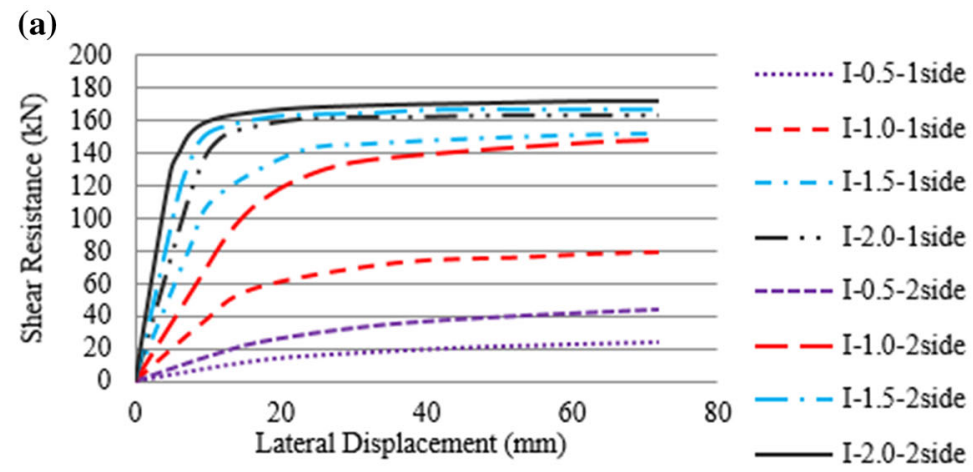

(b)
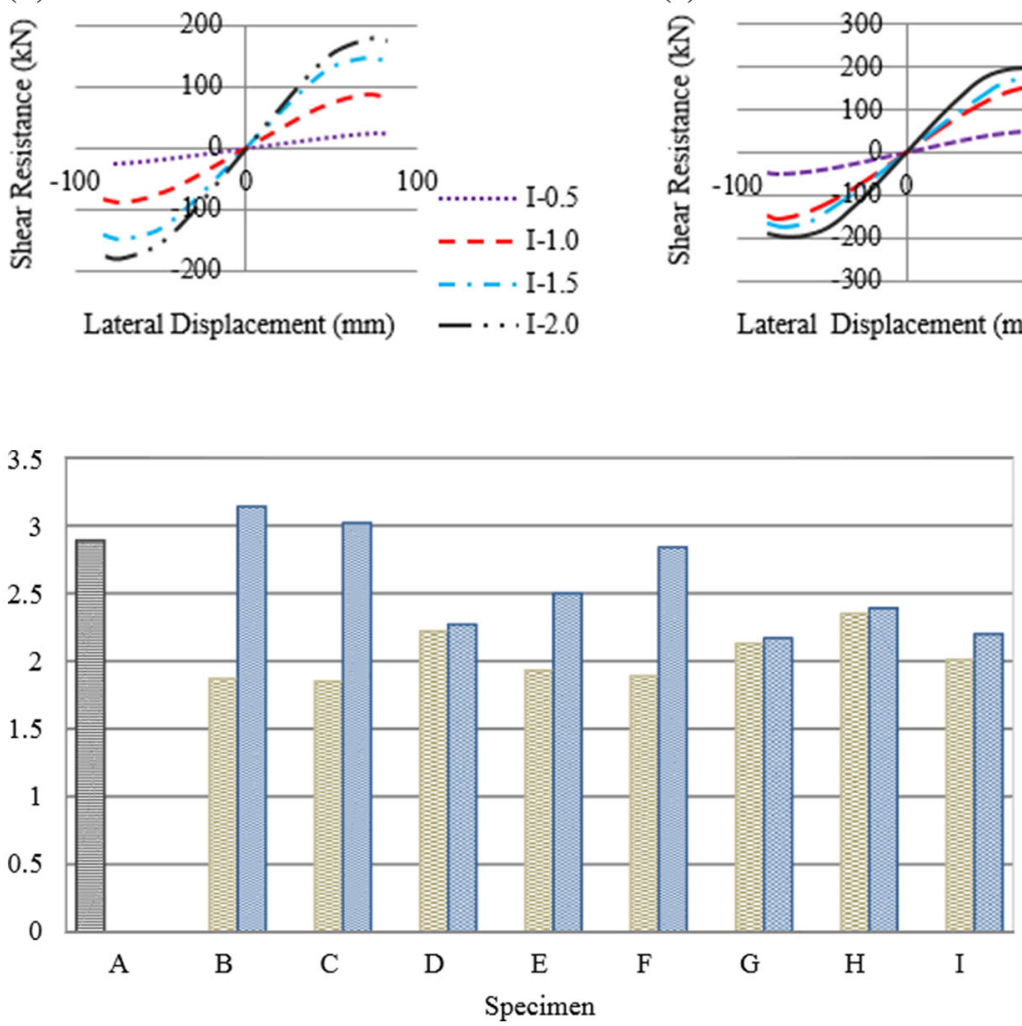

(c)

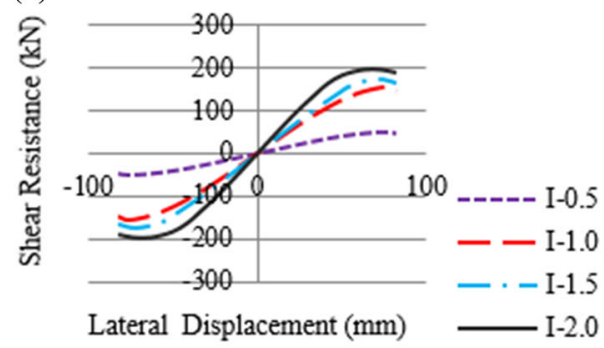

目Whitout Brace

冈 1 side Braced

ㄴ 2 side Braced 
Fig. 17 Maximum strength of the specimens $(\mathrm{kN})$

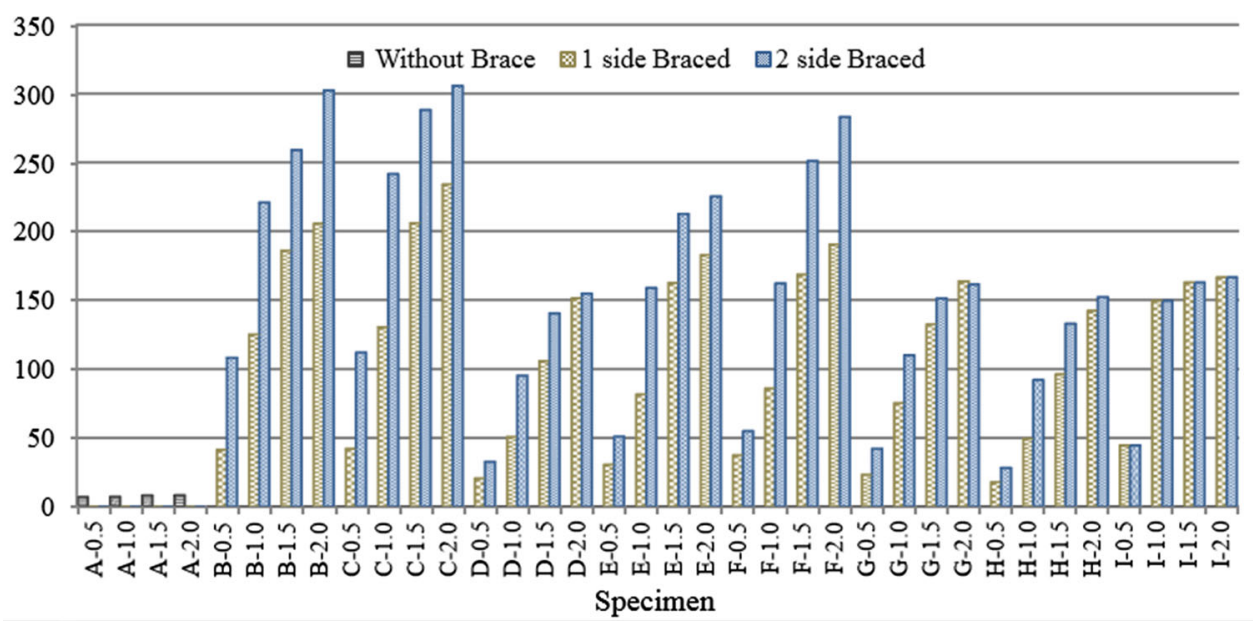

Fig. 18 Maximum lateral drift ratio $(\%)$

Fig. 19 Energy percent of specimens: a 1-side, b 2-side
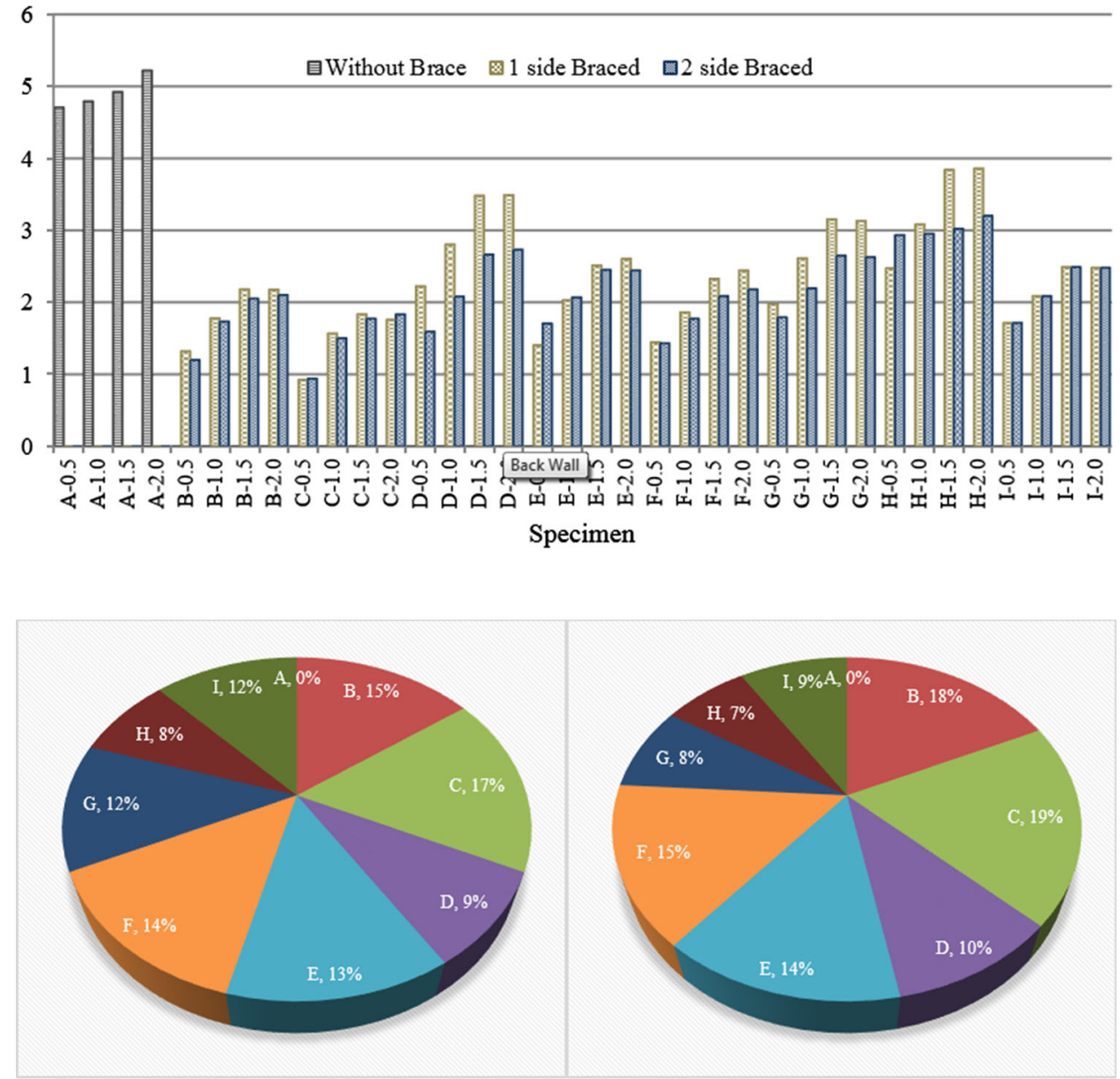

(a) (b)
(Table 9). To calculate the value of $\left(R_{\mathrm{d}}\right)$ for wall with bilateral brace, a mean value of ductility equal to 2.85 was used and the value of $R_{\mathrm{d}}$ was evaluated equal to 2.17. Since the value of $\left(S_{\mathrm{y}} / S_{\mathrm{yp}}\right)$ is less than 1 , there is no additional resistance; thus the value of $\left(R_{0}\right)$ is considered equal to 1 . Finally, the value of the response modification factor was obtained as 2.17 for sample $G$ with bilateral brace (Table 9). If the bilateral brace is used for sample $\mathrm{G}$, the value of the response modification factor will be about $1.87 \%$ more than that of the lateral brace. This small difference can result from the lack of additional resistance in samples. 
The value of predicted stiffness was 13.18 and $19.06 \mathrm{kN} / \mathrm{mm}$, respectively, for samples $\mathrm{G}$ with lateral and bilateral braces under monotonic loading (Tables 5, 6) and 18.30 and $19.47 \mathrm{kN} / \mathrm{mm}$, respectively, under cyclic loading (Tables 7,8$)$. Obviously, the value of $\left(K_{\mathrm{e}}\right)$ is considerably less than $\left(K_{\mathrm{p}}\right)$. The shear resistance is increased by increasing the ratio of the height to length of the wall. On the other hand, the shear wall resistance of the bilateral brace was significantly more than that of the lateral brace. This has been clearly shown in Fig. 13a-c.

By increasing the rate of height to length of the wall, the elastic stiffness and stiffness values are expected to increase and the amount of plasticity decreased. Using double straps will improve strength, stiffness and ductility.

\section{Numerical analysis of frames of samples $\mathbf{H}$}

The mean value of yielding capacity under monotonic loading of samples $\mathrm{H}$ with lateral and bilateral braces was obtained as 60.49 and $83.24 \mathrm{kN}$, respectively, which has been predicted equivalent to 74.93 and $79.30 \%$ of capacity values (Tables 5, 6). The mean value of yielding capacity under cyclic loading of samples $\mathrm{H}$ with lateral and bilateral braces was obtained as 64.40 and $89.38 \mathrm{kN}$, respectively, and also the ratio of $\left(S_{\mathrm{y}} / S_{\mathrm{yp}}\right)$ was obtained as 71.90 and $114.73 \%$, respectively (Tables 7,8 ). The value of the yielding capacity of bilateral brace is around $38 \%$ more than that of the lateral brace. Sample $H$ with a lateral brace could not get the total of predicted yielding capacity and, at the moment of wall failure, braces did not reach the total of the yielding capacity; however, the status of the bilateral brace sample has somewhat improved compared to that of the lateral brace sample and it could get the total of predicted capacity under cyclic loading. For the ratio of yielding capacity to the nominal yielding capacity, the mean value was 57.60 and $79.28 \%$, respectively (Tables 5, $6)$, under monotonic loading of these samples with lateral and bilateral braces and 61.33 and $85.12 \%$, respectively (Tables 7, 8), under cyclic loading. These values show that samples $\mathrm{H}$ with lateral and bilateral brace could not get the expected nominal design shear resistance.

The mean value of $\left(\Delta_{0.8}\right)$ was evaluated as 80.90 and $73.89 \mathrm{~mm}$, respectively (Tables 5, 6), under monotonic loading of samples $\mathrm{H}$ with lateral and bilateral braces and 78.90 and $76.27 \mathrm{~mm}$, respectively (Tables 7, 8), under cyclic loading. The presence of bilateral brace on the wall causes about $6 \%$ reduction on its maximum displacement compared to lateral brace samples. The mean value of ductility was evaluated as 3.16 and 3.22, respectively (Tables 5, 6), under monotonic loading of samples $\mathrm{H}$ with lateral and bilateral braces and 3.35 and 3.49 , respectively, (Tables 7,8$)$ under cyclic loading. To calculate $\left(R_{\mathrm{d}}\right)$ from Eq. (3) for wall with lateral brace, a mean value of ductility equal to 3.26 was used and the value of $R_{\mathrm{d}}$ was evaluated as 2.35 . Since the value of $\left(S_{\mathrm{y}} / S_{\mathrm{yp}}\right)$ is less than 1 , there is no additional resistance; thus the value of $\left(R_{0}\right)$ is considered equal to 1 . Finally, the value of the response modification factor was obtained as 2.35 (Table 9). To calculate the value of $\left(R_{\mathrm{d}}\right)$ for wall with bilateral brace, a mean value of ductility equal to 3.36 was used and the value of $R_{\mathrm{d}}$ was equal to 2.39. Since the value of $\left(S_{\mathrm{y}} / S_{\mathrm{yp}}\right)$ is less than 1 , there is no additional resistance; thus the value of $\left(R_{0}\right)$ is considered equal to 1 . Finally, the value of the response modification factor was obtained as 2.39 for sample $H$ with bilateral brace (Table 9). If the bilateral brace is used for sample $H$, the value of the response modification factor will be about $1.70 \%$ more than that of the lateral brace. This small difference can result from the lack of additional resistance in samples.

The value of the predicted stiffness was obtained as 8.30 and $16.25 \mathrm{kN} / \mathrm{mm}$, respectively for samples $\mathrm{H}$ with lateral and bilateral braces under monotonic loading (Tables 5, 6) and 11.03 and $11.74 \mathrm{kN} / \mathrm{mm}$, respectively, under cyclic loading (Tables 7, 8). Obviously, the value of $\left(K_{\mathrm{e}}\right)$ is considerably less than $\left(K_{\mathrm{p}}\right)$. The shear resistance is increased by increasing the ratio of the height to length of the wall. On the other hand, the shear wall resistance of the bilateral brace was significantly more than the lateral brace. This has been clearly shown in Fig. 14a-c.

\section{Numerical analysis of frames of samples I}

The mean value of yielding capacity under monotonic loading of samples I with lateral and bilateral braces was 86.21 and $108.61 \mathrm{kN}$, respectively, which has been predicted equivalent to 74.73 and $78.78 \%$ of capacity values (Tables 5, 6). The mean value of yielding capacity under cyclic loading of samples I with lateral and bilateral braces was obtained as 91.87 and $116.92 \mathrm{kN}$, respectively, and also the ratio of $\left(S_{\mathrm{y}} / S_{\mathrm{yp}}\right)$ was obtained as 74.67 and $112.10 \%$, respectively (Tables 7,8 ). The value of the yielding capacity of bilateral brace was around $26 \%$ more than that of the lateral brace. sample I with a lateral brace could not get the total of predicted yielding capacity and, at the moment of wall failure, braces did not reach the total of the yielding capacity; however, the status of bilateral brace sample has somewhat improved compared to that of lateral brace sample and it could get the total of predicted capacity under cyclic loading. For the ratio of yielding capacity to the nominal yielding capacity, the mean value was 82.11 and $103.44 \%$, respectively (Tables 5,6 ), under monotonic loading of these samples with lateral and bilateral braces and 87.49 and $11.35 \%$, respectively (Tables 7,8 ), under cyclic loading. These values show that samples I with bilateral brace could get the expected nominal design shear resistance well. 
The mean value of $\left(\Delta_{0.8}\right)$ was evaluated as 57.75 and $53.53 \mathrm{~mm}$, respectively (Tables 5,6 ), under monotonic loading of samples I with lateral and bilateral braces and 56.42 and $54.55 \mathrm{~mm}$, respectively (Tables 7,8 ) $\mathrm{mm}$ under cyclic loading. The presence of bilateral brace on wall causes about $5.3 \%$ reduction on its maximum displacement compared to lateral brace samples. The mean value of ductility was evaluated as 2.23 and 2.37 , respectively (Tables 5,6 ), under monotonic loading of samples I with lateral and bilateral braces and 2.36 and 2.46 , respectively (Tables 7,8 ), under cyclic loading. To calculate $\left(R_{\mathrm{d}}\right)$ from Eq. (3) for wall with lateral brace, a mean value of ductility equal to 2.52 was used and the value of $R_{\mathrm{d}}$ was evaluated as 2.01 . Since the value of $\left(S_{\mathrm{y}} / S_{\mathrm{yp}}\right)$ is less than 1 , there is no additional resistance; thus the value of $\left(R_{0}\right)$ is considered equal to 1 . Finally, the value of the response modification factor was obtained as 2.01 (Table 9). To calculate the value of $\left(R_{\mathrm{d}}\right)$ for wall with bilateral brace, a mean value of ductility equal to 2.62 was used and the value of $R_{\mathrm{d}}$ was equal to 2.06. Based on values of $\left(S_{\mathrm{y}} / S_{\mathrm{yp}}\right)$, the mean value of additional resistance $\left(R_{0}\right)$ was equal to 1.07 for the wall with bilateral brace and, finally, the value of the response modification factor was 2.20 for sample I with bilateral brace (Table 9). If the bilateral brace is used for sample I, the value of the response modification factor will be about $9.45 \%$ more than that of the lateral brace. This small difference can result from the lack of additional resistance in samples.

The value of predicted stiffness was 14.58 and $19.57 \mathrm{kN} / \mathrm{mm}$, respectively, for samples I with lateral and bilateral braces under monotonic loading (Tables 5,6) and 20.79 and $22.11 \mathrm{kN} / \mathrm{mm}$, respectively, under cyclic loading (Tables 7,8$)$. Obviously, the value of $\left(K_{\mathrm{e}}\right)$ is considerably less than $\left(K_{\mathrm{p}}\right)$. The shear resistance is increased by increasing the ratio of the height to length of the wall. On the other hand, the shear wall resistance of bilateral brace was significantly more than the lateral brace. This has been clearly shown in Fig. 15a-c.

By increasing the rate of height to length of wall, the elastic stiffness and stiffness values are expected to increase and the amount of plasticity decreased. Using double straps will improve strength, stiffness and ductility.

\section{Comparing values of response modification factors for samples}

The results relating to values of the response modification factor for all samples have been collected in Table 9 and its diagram can be qualitatively observed in Fig. 16. Sample B with bilateral brace was allocated the highest value of response modification factor.

\section{Comparing maximum drift and resistance of the samples}

A qualitative comparison has been given in Figs. 17 and 18 to compare the maximum resistance and drift of samples at a glance. As it is clear, samples with bilateral brace include maximum value of resistance and samples without brace have minimum value of resistance. Among samples with bilateral brace, sample $\mathrm{C}$ with dimension ratio of 2 has the highest value of resistance. However, samples without brace have the maximum value of drift and samples with bilateral brace have the lowest drift.

\section{Comparing the mean energy contribution of the samples}

The energy absorption capability in sample $\mathrm{C}$ is on average more than that of the other samples, and this shows that for sample $\mathrm{C}$, reduction in the resistance stiffness and erosion is lower than that of the other samples. From Fig. 19a-b, it may be noted that the value of energy absorbed in the sample without brace is insignificant compared to other samples.

\section{Conclusions}

Among the studied samples, sample $\mathrm{C}$ was allocated the maximum mean of yielding resistance, $S_{\mathrm{y}}$, the highest mean of predicted stiffness and the highest percentage of energy absorption capability. It is clear that the minimum value of these parameters was related to sample A that was wall without brace. The maximum and minimum mean ratio of $S_{\mathrm{y}} / S_{\mathrm{yp}}$ was related to samples $\mathrm{A}$ and $\mathrm{D}$, respectively. The maximum and minimum mean ratio of $S_{\mathrm{y}} / S_{\mathrm{yp}}$ was also observed in samples $\mathrm{C}$ and $\mathrm{A}$, respectively. In wall without brace, the maximum and minimum drifts were observed in samples A and C, respectively. Generally, samples with lateral brace could not get total of predicted yielding capacity and, at the moment of wall failure, braces did not reach the total yielding capacity; however, the status of bilateral brace samples has somewhat improved compared to that of lateral brace samples and could get the total predicted capacity in cyclic tests. In both modes of unilateral and bilateral braces, samples $\mathrm{C}$ and $\mathrm{B}$ have been able to gain the predicted nominal design shear resistance. Also, in the mode of bilateral brace, sample F could get the expected nominal design shear resistance well, and in the mode of lateral brace, it largely succeeded, but not entirely. Samples E and I could obtain the expected nominal design shear resistance only in bilateral brace mode. In all samples, the value of $K_{\mathrm{e}}$ was considerably less than that of $K_{\mathrm{p}}$. 
In bilateral brace, the maximum response modification factor was 3.14 for sample B and 2.35 for sample H. It was also observed that the presence of lateral or bilateral brace had no significant difference in the value of response modification factor for samples D, G, H and I. In the wall without brace, a high ductility was observed compared to the other samples, but no additional resistance was observed in this sample. In all samples, the shear resistance increased by increasing the ratio of wall height to length and the shear resistance of wall with bilateral brace was $60 \%$ more than the lateral brace.

Open Access This article is distributed under the terms of the Creative Commons Attribution 4.0 International License (http:// creativecommons.org/licenses/by/4.0/), which permits unrestricted use, distribution, and reproduction in any medium, provided you give appropriate credit to the original author(s) and the source, provide a link to the Creative Commons license, and indicate if changes were made.

\section{References}

AISI (2001a) Standard for cold-formed steel framing-prescriptive method for one and two family dwelling. American Iron and Steel Institute, Washington, DC

AISI (2001b) North American specification for the design of coldformed steel structural members. American Iron and Steel Institute, Washington, DC

Al-Kharat M, Rogers CA (2007) Inelastic performance of coldformed steel strap braced walls. J Constr Steel Res 63(4):460-474

AS/NZS4600 (2005) Cold-formed steel structures. Australian Building Codes Board, Canberra

ASCE7-05 (2005) ASCE7-05 minimum design loads for buildings and other structures, American Society of Civil Engineers

ASTM E2126 (2005) Standard test methods for cyclic (reversed) load test for shear resistance of framed walls for buildings. ASTM International, West Conshohocken

ASTM-E2126-07 (2007) Standard test methods for cyclic (reversed) load test for shear resistance of walls for buildings. USA, p 13

Berman JW, Celik OC, Bruneau M (2005) Comparing hysteretic behavior of light-gauge steel plate shear walls and braced frames. Eng Struct 27(3):475-485

Dabreo J, Balh N, Ong-Tone C, Rogers CA (2014) Steel sheathed cold-formed steel framed shear walls subjected to lateral and gravity loading". Thin Walled Struct 74:232-245

FEMA-450 (2003) NEHRP recommended provisions for seismic regulations for new buildings and other structures-part 1 provisions. Building Seismic Safety Council, USA

FEMA-P750 (2009) NEHRP recommended seismic provisions for new buildings and other structures. Building Seismic Safety Council, Washington, DC

Fiorino L, Iuorio O, Landolfo R (2012) Seismic analysis of sheathingbraced cold-formed steel structures. Eng Struct 34:538-547
Fülöp LA, Dubina D (2004) Performance of wall-stud cold-formed shear panels under monotonic and cyclic loading part I: experimental research. Thin Walled Struct 42(2):321-338

Gad EF, Chandler AM, Duffield CF, Hutchinson GL (1999a) Earthquake ductility and overstrength in residential structures. J Struct Eng Mech 8(4):361-382

Gad EF, Duffield CF, Hutchinson GL, Mansell DS, Stark G (1999b) Lateral performance of cold-formed steel-framed domestic structures. J Eng Struct 21(1):83-95

Kim TW, Wilcoski J, Foutch DA, Lee MS (2006) Shaketable tests of a cold-formed steel shear panel. J Eng Struct 28(10):1462-1470

Miller TH, Pekoz T (1993) Behavior of cold-formed steel wall stud assemblies. J Struct Eng 119(3):641-651

Moghimi H, Ronagh HR (2009) Performance of light-gauge coldformed steel strap-braced stud walls subjected to cyclic loading. Eng Struct 31(1):69-83

MSC Software (2012) MSC Nastran 2012 Users Guide. MSC Software

National Research Council of Canada (NRCC) (2005) National Building Code of Canada. Ottawa, ON

Newmark N, Hall W (1982) Earthquake spectra and design. Earthquake Engineering Research Institute, Berkeley, California, p 170

Nithyadharan M, Kalyanaraman V (2012) Modelling hysteretic behaviour of cold-formed steel wall panels. Eng Struct 46:643-652

Pan ChL, Shan MY (2011) Monotonic shear tests of cold- formed steel wall frames with sheathing. Thin Walled Struct 49:363-370

Serrette RL (1997) Additional shear wall values for light weight steel framing Report No. LGSRG-1-97, Santa Clara University, Santa Clara, CA

Telue T, Mahendran M (2002) Behavior of cold-formed steel wall frames lined with plasterboard. J Constr Steel Res 57(4):435-452

TI 809-07 (1998) Design of cold-formed loadbearing steel systems and masonry veneer/steel stud walls. US Army Corps of Engineers, Engineering and Construction Division, USA

Zeynalian M, Ronagh HR (2010a) Performance of K-braced coldformed steel shear walls subjected to lateral cyclic loading. In: Zingoni A (ed) Advances and trends in structural engineering mechanics and computation. CRC Press, London

Zeynalian M, Ronagh HR (2010b) Performance of knee braced coldformed steel shear walls subjected to lateral cyclic loading. In: Proceedings of the 20th international specialty conference for cold-formed steel structures, Missouri University of Science and Technology, St. Louis, MO

Zeynalian M, Ronagh HR (2011) A numerical study on seismic characteristics of knee-braced cold formed steel shear walls. Thin Walled Struct 49:1517-1525

Zeynalian M, Ronagh HR (2012a) A numerical study on seismic performance of strap-braced cold-formed steel shear walls. ThinWalled Struct 60:229-238

Zeynalian M, Ronagh HR (2012b) A numerical study on seismic characteristics of knee-braced cold formed steel shear walls. Thin Walled Struct 49:1517-1525

Zeynalian M, Ronagh HR, Hatami S (2012) Seismic characteristics of K-braced cold-formed steel shear walls. J Constr Steel Res 77:23-31 